\title{
Proceedings of the workshop on integrating reproductive tract infection case management in LGU health centers
}

Population Council

Follow this and additional works at: https://knowledgecommons.popcouncil.org/departments_sbsr-rh

Part of the Community Health and Preventive Medicine Commons, and the International Public Health Commons

How does access to this work benefit you? Let us know!

\section{Recommended Citation}

"Proceedings of the workshop on integrating reproductive tract infection case management in LGU health centers." Manila: Population Council, 1997. 
Proceedings of the

\section{WORKSHOP ON INTEGRATING \\ REPRODUCTIVE TRACT INFECTION CASE \\ MANAGEMENT IN LGU \\ HEALTH CENTERS}

March 18-21, 1997

Lauremar Beach Resort

Opol, Cagayan de Oro City

Sponsored by

Family Planning Service

Department of Health

Republic of the Philippines

and

Family Planning Operations Research and Training (FPORT) Program

Population Council, Manila

Asia \& Near East Operations Research

and Technical Assistance (ANE/OR/TA) Project ${ }^{1}$

December, 1997

${ }^{1}$ The ANE OR/TA Project is funded by the US Agency for International Development, Office of Population, Health and Nutrition, under Contract No. DPE-3030-Q-00-0023-00. 


\section{ACKNOWLEDGMENT}

The support of the Department of Health, as well as of the local government units of Quezon City, Cagayan de Oro, Jasaan and Tagoloan, Misamis Oriental is gratefully acknowledged in the conduct of the RTI Case Management Training Workshop. Population Council would also like to thank DKT International, Cebu City Health Office, and WEDPRO for sharing their resources during the training.

This study is supported by the Population Council's ANE OR/TA project. The ANE OR/TA project is funded by USAID Contract No. DPE-3030-Q-00-0023-00. 


\section{TABLE OF CONTENTS}

\section{Page}

Acknowledgment

ii

Executive Summary $\quad$ v

Welcome Address

Dr. Avelino Grospe

1

Regional Director

Department of Health

Region $X$

Integrating RTI Management

Dr. Marilou P. Costello

in LGU Health Centers:

Host Country Advisor

Background of the Project

The Population Council

Presentation of FGD Results

Ms. Carmeli Marie Chaves

Research Associate

The Population Council

Presentation of Situation

Dr. Jesus Encena, Jr.

Analysis Results (I)

OR Country Fellow

The Population Council

Open Forum

Presentation of Situation

Ms. Carmeli Marie Chaves

Analysis Results (II)

Overview of Reproductive

Dr. Jesus Encena, Jr.

Tract Infections

History Taking, Physical

Examination and Review of

the Human Reproductive

Dr. Erickson San Juan

Anatomy

STD/AIDS Program

Coordinator

City Health Office,

Cag. De Oro City

Open Forum 
Reproductive Tract Infections

Causes of Genital Discharges

and Ulcers

Open Forum

Genital Skin Conditions and HIV/AIDS

Pelvic Inflammatory Disease and Introduction to Laboratory Methods in RTI Case Management

Introduction to the Syndromic

Management of RTIs

Gender Awareness and Sensitivity

Integrated RTI/FP Counseling

IEC and Community Awareness

Campaigns

Context of the RTI Management

Integration Project: Components,

Expected Outcomes, and

Methodology

Plans of Integration

Closing Remarks

Appendices

List of participants

Pictorial Documentation
Dr. Ilya Abellanosa

46

Social Hygiene Clinic

City Health Office

Cebu City

Dr. Erickson San Juan

62

Dr. Jesus C. Encena

67

Dr. Ilya Abellanosa

71

Ms. Aida Santos

74

Consultant, WEDPRO

Ms. Rhea Ravanera

82

DKT International

Ms. Sol Atayan

DKT International

Dr. Marilou P. Costello

91

96

Dr. Nemesio Gako

104
Assistant Secretary

Department of Health

Manila 


\section{EXECUTIVE SUMMARY}

This report documents the proceedings of the training workshop for physicians, nurses and midwives in selected health centers of the country on RTI case management. Various consultants from the Department of Health (DOH) - Family Planning Service and STD-AIDS Unit, DKT International, DOH Region X Office and the Social Hygiene Clinics of the cities of Cagayan de Oro and Cebu served as trainors in the workshop. The main references used for this training are the manuals developed by WHO and the National STD Guidelines developed by AIDSCAP endorsed by the Department of Health.

Twenty-one participants attended the training, of which seven are physicians and 14 are nurses and midwives.

The training started with the presentation of the FGD results emphasizing existing beliefs and perceptions of the community regarding RTIs. Several misconceptions on RTIs were found in this study, which emphasized the need for community awareness, counseling, and IEC materials on RTIs.

The results of the situation analysis served as an eye opener for many in that clients with RTI-related symptoms were found to be rather rare and not systematically managed in the health clinics. Many providers report that since they are not trained to handle such cases, they refer whoever comes with symptoms to the hospital or to private practitioners.

The open forum sessions revealed preconceived notions and initial confusion regarding RTI management held by service providers. The discussions centered on such issues as managing commercial sex workers with RTIs, whether nurses and midwives should be allowed to provide treatment for RTIs, and ensuring drug provision. Concerns were also raised on how to tell the client about sensitive matters during counseling and how to convince her sex partner to come to the clinic for treatment. 
The participants were trained in history taking, physical examination, and management RTIs, which were grouped according to the presenting symptoms. Laboratory methods in RTI diagnosis such as wet mount and gram staining were reviewed. The providers were also oriented on the different RTI syndromes and the corresponding management endorsed by the $\mathrm{DOH}$. To guide the services providers on giving the appropriate messages to the client and the community, sessions on integrated RTI/FP counseling and community awareness were included.

The training of service providers in RTI management is the first of several components of the RTI integration study. The project also includes strengthening community education campaigns, upgrading laboratory facilities in the clinics, and ensuring the provision of RTI drugs. The expected outcomes of the project are an increase in the proportion of women who receive RTI services, who seek information on the prevention and treatment of RTIs, who receive counseling and information on RTIs, and who are referred for diagnosis and treatment in the intervention clinics. It is also expected that the diagnostic facilities for RTIs will be more comprehensive in these clinics.

The data collection procedures, composed mainly of a comparison of intervention and non-intervention clinics and follow-up procedures such as examining clinic records and conducting exit interviews were briefly reviewed. Towards the end the different groups drew up their plans of integration following the project timetable. These plans were made after a self-assessment of the perceived strengths and limitations of each clinic. The workshop ended with a brief message from the DOH Assistant Secretary. 


\title{
WELCOME ADDRESS
}

\author{
Dr. Avelino Grospe \\ Regional Director \\ Department of Health-Region X
}

Your banner says, "Maayong Pag-abot", which means "Welcome" in Cebuano. It is a delight to be with you this morning. The significance of this gathering here today cannot be overemphasized because the topic of this conference is so important. I understand that you will be discussing how to integrate RTI Case Management into LGU Health Centers.

I know that this group is composed of physicians, nurses, midwives and others who already have a good background on this subject matter. Perhaps what is important is for us to think and see the relevance of the learning that we will get from this four-day activity . Will it be possible to integrate a new type of service within our existing programs? How relevant is it to our community? How will it affect us individually as health workers? Will it help us make our work simpler? More interesting? Or perhaps more challenging?

I hope that your four days here will be a very fruitful experience and will provide added learning to all of you. Many have been asking me questions about why we keep training people. Local executives have started to question this, especially now in our devolved setting. We explained to them that, after devolution, the DOH was mainly tasked with the giving of technical assistance in matters pertaining to health care. While it is true that many already have the basic knowledge in these areas, new ideas and emphases come up all the time, so there is a constant need for us to update ourselves. It may not be on the theoretical side that we need updating, as it could just be a case of bringing personnel up-todate on current approaches and efficient ways of delivering services.

With these thoughts, I would like to welcome you all to Cagayan de Oro. I would like to thank all our facilitators and the Population Council for making this activity possible, and for having invited so many of our people. 
I am happy to hear that we also have a group coming from Metro Manila. We welcome you to Cagayan de Oro. Please feel free to tell us how we can be of help in anything. Actually, this welcome speech is especially for those who have come from faraway places, like Quezon City. Maybe this is your first time to visit Cagayan de Oro, and perhaps it will convince you to change your thinking about Mindanao. What you will see here in Cagayan de Oro is not very different from what you can see in any of the urban centers of Mindanao. With all the advances in communications and transportation, the Philippines has become a very small country. If you want to go back to Manila, in only an hour and 25 minutes, you will be there. That's an even shorter time than it takes to travel from Quezon City Hall to the Central Office of the DOH, if we take into account the infamous traffic jams of Metro Manila. I hope your coming to Cagayan de Oro will prove a respite from this.

Again, welcome to all of you, and good day. 


\title{
INTEGRATING RTI MANAGEMENT IN LGU HEALTH CENTERS: BACKGROUND OF THE PROJECT
}

\author{
Dr. Marilou Palabrica-Costello \\ Host Country Advisor \\ The Population Council
}

\begin{abstract}
Good morning to all of you. My task this morning is to give a background of the study, but before I would do that, I would like to join Dr. Grospe in welcoming all of you to Cagayan de Oro and to this training workshop on case management and treatment of RTI.
\end{abstract}

The Department of Health and the Population Council are supporting this activity as part of a one-year intervention study to assess the feasibility of integrating reproductive tract infection services within existing Family Planning/ Maternal and Child Health programs. It is in the context of this research that this RTI training is being held. I would like to emphasize that this training is not an isolated activity. It is part of a research program which we are implementing and pilot-testing in selected LGU centers all over the country. We have selected a few places which we think are representative of the country. Quezon City was chosen, for example, because we think that it is a good representative of a large urban area. We have chosen Cagayan de Oro to represent a medium-sized city and Misamis Oriental to represent a province, so as to be able to illustrate the situation in a rural health clinic. Having the training here is therefore a first step towards implementing this study.

At this point, I want to present to you the conceptual framework that will guide us in this study, as shown on this overhead. You can note that the box which I have highlighted with a red pen is the intervention program. The intervention program here consists of a series of activities that we plan to undertake in these identified LGU health centers, including enhancing provider skills for case management and for implementing this program. Today's training is part of a series of activities that we are undertaking to enhance service provider's capacity to handle RTI cases. There will also be several other activities that we 
will discuss with you towards the end of the workshop. For the purposes of this morning, however, this is where I would like to situate today's RTI training.

We are hoping that the intervention program will work towards influencing our intermediate variables. We expect that the set of intervention activities will raise the quality of reproductive health services. We also hope that these activities will increase health seeking behavior and prevention and management of RTI and STDs, both from the clients' and on the side of the provider. We are hoping as well to increase the number of referrals for RTI and STD treatment as a result of these intervention activities. And of course, the fourth area that we hope to influence is an improvement in the RTI and STD diagnostic facilities of these different LGUs. We hope that these four sets of factors: the quality of services, the improvement of health-seeking behavior, the increase in referrals for RTI/STD treatment, and the improvement in the diagnostic facilities -- would improve RTI case finding and management and increase the incidence of preventive behaviors on the part of the client.

Why is there such a big concern about management of reproductive tract infections? This concern is actually borne out of the global support for reproductive health found in the International Conference for Population and Development Plan of Action which was drafted at the Cairo Conference of 1994, and of which the Philippine government is a co-signatory. RTIs encompass iatrogenic infections, endogenous infections and sexually transmitted diseases. We would therefore like to emphasize that we are not just talking about STDs here. The definition includes the two other types of infections. It has also been shown that the consequences of reproductive tract infections are quite serious, as they include post-abortal puerperal sepsis, ectopic pregnancy, fetal and prenatal death, infertility and social rejection, among others. 
It is also a fact that RTIs are extremely widespread. They are not just found among the so-called "high risk" groups like commercial sex workers. In fact, a famous study called the Giza study revealed that more than half the women in the general population were actually suffering from some form of RTI, most commonly vaginitis. This contradicts the misconception that only a few special groups can get RTIs. It is almost certainly quite widespread in the Philippines but we just lack actual documentation of this. We do have some anecdotal evidence that the situation in Giza is also happening here, but we have yet to have the type of systematic study that was done over there to provide us with concrete evidence.

So why are we trying to integrate RTI services in our LGU health centers, particularly within the context of family planning? We are doing this because RTIs can work to decrease the demand for family planning, as well as to bring about family planning discontinuation once the symptoms that women feel are perceived as side effects of contraceptive use. On the other hand, potential family planning clients may be refused services (usually for IUD or ligation) until their infections are treated. It is clear that RTI services are a logical and necessary complement to existing family planning and maternal health programs.

You may know that there are several other initiatives dealing with RTIs going on in the country. In fact, Director Grospe has just mentioned that he is also going to a workshop similar to this one. However, there are as yet no attempts to study how feasible it is to integrate this type of services into the public sector health clinics. Director Grospe was asking earlier if it would make our work simpler if we integrate this service. I have the suspicion that it will not make your lives simpler, but hopefully it is going to make your work more useful and responsive to the people that you are serving.

We are also interested in looking at questions like, how much will it cost to provide this service? We would like to observe the places we have selected for a year and see how much it will cost if we will provide these services. This information can help policy 
makers and program managers in terms of planning for the future implementation of this service. Will it serve to strengthen, or perhaps even weaken existing programs of health clinics? These are the types of questions that we hope in this study will provide some answers.

We are therefore very gratified that you have joined us in this important activity. Whatever the result of this study will be, it is clear that our training these next few days will go a long way towards addressing the urgent needs of men and women in the area of reproductive health. I'd like to thank you and I wish every one of us a very productive workshop. Thank you. 


\title{
PRESENTATION OF FGD RESULTS
}

\author{
Community Beliefs and Perceptions of Reproductive Tract Infections \\ Ms. Carmeli Marie Chaves \\ Research Associate \\ The Population Council
}

\begin{abstract}
At this point we would like to let you know about the results of the focus group discussions that we conducted several months ago. A Focus Group Discussion or FGD is a qualitative method of data collection, usually conducted among 8-10 participants in a group, to get the views, opinions, and attitudes of community members towards a certain topic. FGDs are a useful approach since a group sharing provides for a more congenial setting, so that people are more open as compared to an interview or a survey. More probing is also possible in a FGD.
\end{abstract}

We did twelve FGDs, four in Quezon City, four in Cagayan de Oro, and four in Misamis Oriental. In each group we held one FGD for the older women, aged 31-45, one for the younger women, aged 18-30. There was also one each for both younger men and older men.

We asked psychology professors from UP Diliman and researchers from the Health Action Information Network to serve as facilitators, as well as graduate students from the UP Population Institute to work as documenters. Local nurses and researchers helped us in conducting the FGDs in Cagayan de Oro and Misamis Oriental.

The flow of the FGD was covered by the topic guide. First, we asked them about their knowledge concerning RTIs. Next, we asked them about their practices, healthseeking behaviors, and their sources of information about RTIs. We also asked about the factors that prevent or encourage them to seek services at the health center. 
We next asked them what kind of a service provider they would like to have. We wanted to get the community's perception of the quality of service delivery at the health center. That is why we asked the community members to join the FGD, but held separate sessions for males and females because we knew that with a topic like RTIs, certain biases and prejudices only come out when they are among persons of the same gender. Then we also asked them about how they would notify their partners and how they make decisions about seeking health service. The use of family planning methods and their connections to RTIs, if any, were discussed. We also asked their opinions about using condoms. The last topic was not originally included in the topic guide, but the participants spontaneously brought up gender issues that were perceived to be relevant to their seeking service at the health center.

Let me start first with the misconceptions. The FGDs uncovered a lot of misconceptions about the nature of RTIs. Many confused them with urinary tract infections. Many were also confused about the symptoms of RTIs. They could name the symptoms, but not the specific RTIs. Vaginal discharge and itching was frequently cited by the women as a symptom, while the men mentioned painful urination, genital sores, pubic lice, and pus in urine. The older women also believed that RTIs happen mostly to men who engage in extramarital affairs. It seems they did not realize that it could also happen to them under ordinary circumstances. They also believed that taking too much antibiotics as treatment can kill or weaken the sperm.

What were the local terms used for the symptoms? Frequently mentioned was tulo, especially for the Quezon City women. In Visayan, they used sira, or nasira. Also in Cagayan de Oro and Misamis Oriental, they used terms like "Vietnam rose" for gonorrhea, and they mentioned nuka-nuka or samad, meaning pus. Sometimes they used korikung to refer to scabies. "Nana” (pus), was also frequently cited, as well as "tuway-tuway”. They often called pubic lice “kuto" or "garapata”. 
Let us now go to how they sought health service. What was their health seeking behavior? Both men and women participants in the FGD resorted to a lot of self-medication for RTI symptoms but for different reasons. On one hand, the men did it out of embarrassment and fear of enraging their wives, particularly if the infection was sexually transmitted. Thus, they took measures like swallowing a piece of detergent and then urinating. They also washed the penis with rum. They also made use of "the young coconut treatment", wherein heated young coconut is used to draw out pus from the penis. Pubic lice were killed by applying gasoline or paint thinner to the shaved pubic area. Also mentioned across all groups was the meat poultice treatment: meat is applied to the pubic area in order to attract the lice. Most often though, the men consulted their friends first, especially those who have had experience in treating their own infections and then they took the antibiotics that their peers recommended and which they bought over the counter.

The women, on the other hand, attributed their symptoms to poor personal hygiene. They believed that vaginal itching is caused by unsanitary conditions, unclean surroundings, dirty water, etc. Mild symptoms like vaginal itching were relieved by using a vaginal douche, commonly consisting of warm water and rubbing alcohol, soap, guava leaves, or herbs. Older urban women also believed that when menstruating, they should avoid using sanitary napkins as much as possible. They should wash only with warm kalamansi and shouldn't carry heavy things.

Where did they get this information? The number one answer was stories heard from friends. Second, they also said that they consulted "experienced" friends. The other sources were radio and T.V. shows such as "Magandang Gabi Bayan", which seemed particularly appealing to the masses. In Mindanao, they often listened to the radio show, "Handumanan", where a letter writer sends in his/her story to the station and some sort of advice is given to solve the problem. Finally, they also said that they got information from health workers. One participant in particular mentioned that she learned these things from attending seminars on family planning. 
When did these people go to the health center? The men were particular about privacy in the health center and the confidentiality of the information that they gave to the service provider. Their reluctance to seek RTI treatment in the center was born mainly of two fears: first, they feared being talked about in the community, especially for the fact that the clinic setting could not guarantee visual and auditory privacy, and number two, they feared not getting competent treatment. Thus, the client's main consideration was to receive some assurance that the service provider would keep confidential all the information that she receives and that the client, no matter how needy, will still be treated with respect and compassion. At the same time, clients expected to be given competent service at the clinic. They preferred to be attended to by a specialist, and since in most health centers in the country, an RTI specialist is not available, some would rather seek the services of a private physician.

It was also mentioned in the FGDs that one deterrent to their seeking service at the health center was the long lines that they encountered, especially during important days, such as immunization days. They were concerned with having to line up in order to obtain service. Many of the clients preferred a one-on-one consultation with a service provider whom they personally knew and trusted. If this was not possible, they weighed the severity of the symptoms in seeking RTI treatment and then most men went to a clinic where they were not known. Since they were embarrassed about going to a health center that, according to them, was mostly staffed by women, some went to the extent of going to health centers where they were not known.

What about their expectations of the service provider? What kind of a service provider did they like? The clients preferred to be attended to by a service provider who is capable and experienced in his/her field and who takes the time and effort to listen to them. As for gender, we found this to be a secondary consideration. The clients knew that they may not be able to choose the gender of the service provider who will attend to them in the clinic, although if given such a choice, they would rather be seen by someone of their own 
sex. This was true for both men and women. Ultimately, however, it was provider competence and interpersonal skills that made clients seek treatment in the health center. This means that the provider must be knowledgeable about RTIs and skilled in their treatment, and at the same time, concerned about the client's condition. Provider experience was also important, as clients felt that they should not be used as practice cases for others.

Risk assessment questions were presented to the FGD participants and the general opinion was that such personal questions were acceptable, as long as they were pertinent to the client's complaint. They said that the provider must explain beforehand the need for asking about this type of personal information. Nevertheless, if the client realizes that the information being asked of him/her is necessary for treatment, then he/she is willing to answer such questions. The client will also accept this out of deference to the service provider, especially the physician. Still, the participants insisted on being assured of confidentiality and privacy during consultation. If possible, they would prefer a service provider of their own sex to ask the questions.

Let us now go to whether they notified their partner or not. As for the women, they claimed that they always shared their health complaints with their husbands, even including RTI symptoms. On the other hand, the men were not as open to their wives about this sort of infection. We found out that among the participants, the common belief was that all RTIs are acquired sexually, and that since the wives were not likely to have sexual partners other than the husband, then the most likely conclusion was that the source of the infection must have been the husband. If this was the case, there was a likelihood that marital conflict would happen. Trust is diminished and sexual relations will sour. This was reported in all FGD groups.

When will the wife suspect that the husband has acquired an STD? First, when she notices that he feels weak, avoids sex, and seem to be hiding something. Then, the wife checks the husband's underwear for discharges (which some men have also reported doing 
to their own wives' underwear) and upon confirmation of her suspicions, the wife confronts the husband. Initially, there will be conflict between them, but after a while, the wife will suggest treatment and, if necessary, will accompany the husband for a check-up. Since, as one participant said, the couple promised to be with each other "through sickness and in health", she will go with her husband to the health center.

The picture changes, however, when it is the wife who is suspected of acquiring an STD and who, by implication, was unfaithful. Both men and women participants acknowledged some sort of a double standard in this regard, with the husbands saying that their wives' infidelity would cause them to commit physical aggression and could even be grounds for separation. This is a serious point to consider. Both men and women acknowledged the double standard. If men are not faithful, it can be forgiven because, after all, "they are men", but if the women are at fault, everyone admits that this will be a cause for physical aggression. This is how serious things can get if symptoms are left untreated and if there is no effective mechanism for partner notification.

In sum, if the husband recognizes the symptoms, and he contracted it extramaritally, he keeps it from his wife to avoid trouble, consults his friends and takes the medicines that they recommend. Others go to a private physician who specializes in STDs, and if ever there is a need to inform his wife, he does so, but only after he has recovered. However, if it is the wife who is infected and she believes that she contracted it from her husband, a confrontation is likely to occur, with her asking him how he could afford to have another woman and how he could keep it from her. She discovers his infection and the implied infidelity only once she herself has become infected. One woman remarked during an FGD that "the wife is always the last to know". Most of the time it is the wife who insists that they go to a doctor for treatment and that, in the meantime, they should avoid sexual contact. Since the wife is perceived as the rightful caregiver, it is often she who initiates treatment-seeking. However, older men believe that they should be the ones to decide on what to do and whom to consult. 
Let me take up the last two topics briefly. How did they view family planning methods in relation to RTIs? In Quezon City, the older and some of the younger women recognized that septic abortion and improper IUD insertion can be a cause for RTIs. The use of the pill was also related to RTIs, although the exact relationship was still vague to the participants. Many of the men and women attributed all kinds of ailments and complaints to the use of their FP method. Some linked it to cancer, irritability, disintegration of the uterus, fever, weakness, impotence, and even homosexuality.

What about condom use? What came out was that both men and women in the rural and urban areas do not prefer the condom as an FP method because it was said to decrease sensitivity and decrease vaginal lubrication, causing painful intercourse. What were the things they cited against the condom? They said that the condom was unpleasant to use because it was hot, tight around the penis, smelly, greasy, and its effectivity as an FP method could not be relied upon because they said that it could have holes and it could slip off.

Finally, let me talk about some gender issues. I'd like to quote some women, 35 years and above from Quezon City. "For us women, it is more shameful to be unfaithful than it is for the men. Never mind if the men are unfaithful, but not the woman, no, not us. So we just stay at home. But there are women who fool around and seek shallow happiness. They don't know how to take care of their family. They only care for themselves and not the children because the woman, once married and with children, must act like a martyr. It's difficult if your children are young, but once they have grown up, you can do anything you want." I would also like to quote from a thirty-year old male government employee; "If you have a high regard for your wife, you will treat her as an equal. Then perhaps, you cannot bring yourself to look for someone else." These views on sexuality and gender were spontaneously brought out in the FGDs and were among the livelier parts of the discussion. A salient issue was the differences in the sexes in health-seeking behavior and partner notification, as I described earlier. 
So these are the findings that we gathered in our focus group discussions in Quezon City, Cagayan de Oro, and Misamis Oriental. The findings have direct implications to the work that we do, especially in relation to services in family planning and reproductive health. I hope that you consider all these findings in the next few days as we try to enhance our skills in managing RTI cases and in coming up with a plan of action for improving the services that we give at the health center. What I just presented was just a summary of the FGDs. If you are interested in the complete transcripts, they are available; however, they have not been translated and are still in the local language. Thank you for listening. 


\title{
PRESENTATION OF SITUATION ANALYSIS RESULTS (I) (Inventory of Facilities and Services Provided and Client-Provider Interaction)
}

\author{
Dr. Jesus C. Encena \\ OR Country Fellow \\ The Population Council
}

The situation analysis, or SA, is actually a method of gathering data. The purpose of the SA is to examine the existing methods of service which are being used in the health center. This is very important in the design and the conceptualization of the intervention. Last month we visited your respective health centers and inspected the facilities because we wanted to get a better idea of what things were really like at your level.

The SA was made up of five components. The first of these was the inventory of the facilities. We examined the available facilities of the health centers in order to gauge the readiness of the health center to provide services. The second component was the staff interview. All the staff who were providing family planning services were interviewed. The third component was the client-provider interaction observation. We tried to be as unobtrusive as possible while we were observing these interactions, to make the consultation as natural as possible. The fourth component was the client exit interview. Another social scientist was waiting outside to interview your clients once they finished their consultations with you. The fifth and last component was the interview with clients who had come to the clinic for maternal and child health purposes.

I know that many of you are very interested to find out about the preliminary results of the SA, so let me proceed with the presentation. With regard to the scheduling in the health centers, we found that family planning services are available daily at all the health centers we visited. However, in some health centers, clients are advised not to go to the health centers on immunization days because there are many children who need to be immunized. Still, if a client happens to go to the center on that day, he/she will be 
entertained. Some clinics have special schedules for particular procedures, such as reserving Tuesday mornings for IUD check-ups, but family planning services are always available.

The second question asks whether there was a sign announcing that FP services are available at the health center. Unfortunately, $43 \%$, or three out of the seven health centers we visited, did not have any such sign. Three of the four clinics that did have a sign had it posted inside the center, while one clinic had signs both inside and outside. This is actually very important because if our goal is to improve quality of care, and we want to reach out to our clients and the community, we have to make known what services we really offer. I hope when you go back to your respective health centers and you see that you are in need of such a sign, you will put one up.

Third, on the day of the visit, we observed whether the clinic had the following facilities: piped running water, electricity, sufficient seating for clients, working toilets/latrines, a private area for counseling, and a laboratory area. Most had the first four facilities, but the fifth one, a private area for counseling, was not very common. Only two clinics had this. It is essential that counseling be a one-on-one session and it should be private. Some conducted the counseling even within the hearing distance of others. The laboratory that was mentioned consisted of a table with a microscope and a sink where slide preparation was done. This was found in six of the seven study sites.

As for the staff assigned at the health clinics, all of the health clinics have doctors. However, only four of these were permanently assigned. The other three had scheduled visits to the centers. All of the seven clinics also had nurses and midwives. One health center did not have a medical technologist while five did not have a population program officer. This staff listing is very important because it informs us about current human resources and gives us a better idea of how to tap them for the management of RTIs. 
We also wanted to find out about the health talks that are given and whether these were given in some form such as a mother's class or a bench conference. During the study we were not able to see one carried out, but we do know that these activities are often scheduled.

Were certain conditions including auditory and visual privacy, cleanliness, and adequate light and water maintained in the examination area? This component gave very good results. All of the health centers were able to meet all the requirements except for the requirement of auditory privacy, which was absent in one case. This is defined as having an area where client-provider consultations could not be heard by anyone outside.

As for the family planning equipment inventory, only one health center did not have a complete IUD set. In addition to this, six of the seven clinics had a microscope. Most did not have staining reagents for RTIs while only three had glass slides in the laboratory.

As for the family planning methods offered, all the family planning centers offered pills. Only six offered injectables, and the same number offered IUDs. However, one of those six centers did not have the capacity to insert IUDs. In addition, all the health centers offered condoms, NFP and LAM. One of the reasons not all the health centers offered injectables was because of the fear of side effects which they could not manage and which might prove to be fatal. As for the inability to insert IUDs, the clinics either had no set or lacked lighting and space.

We asked if there was a separate record card for RTI cases and we found out that four out of seven clinics store their FP and RTI records separately. We would really like to emphasize the importance of keeping proper records of RTI cases, as we need to improve the recording system, at least for the benefit of the study. 
We wanted to find out the last time the supervisor visited the health clinic, and we discovered that supervisors do this quite infrequently. Six of the supervisors had visited the clinic within the last three months, while in one, the last visit was six months earlier.

As for the service statistics, we did not find any of RTI statistics because these are not included in either the FP reporting forms or the daily statistics for registration. We are pointing this out to you because it is very important that we have some sort of service statistics for RTIs when we install this intervention.

In general, individual FP records are classified according to the method used and are arranged alphabetically. In fact, all of the health centers that we visited had excellent recording and filing systems. However, we noticed that some of the forms were not completely filled up. I would like to emphasize that the Form 1 is a very important aspect of doing a history and physical examination, especially for the new acceptors. There are findings from the bi-manual exam, for example, in the speculum exam of new acceptors, which could determine which types of contraceptives they should avoid and which contraceptives they can use.

Next, we asked if there were any charges for medical services. None of the clinics charged the clients for services rendered, but four had donation boxes.

We now come to client-provider interactions. We observed a total of forty-two such interactions, with ten of these being there on a first visit, while the remaining thirty-two were follow-up visits. When we looked at the topics covered at this time, the most noteworthy result was that concerns about RTIs/STDs were not discussed during any of the consultations. We also wanted to see if the provider talked about a contraceptive method that offered protection from STDs/RTIs/AIDS during the consultation. Unfortunately, none of the providers were able to mention this during any of the consultations. I certainly hope that these deficiencies will be made up once this training is over. 
As for the performance of pelvic examinations, we were able to observe a total of 11 such exams. In only five of the instances were the clients informed about what was going to happen. While all of the exams were conducted in a private room or area, in five of the instances, someone else was present (aside from the researcher), such as the CHW or another midwife. While all of the providers used sterilized speculums and disposable gloves, only five washed their hands before performing the bi-manual exam. It is very important to correct this situation because we are not only protecting the patient by preventing the transfer of germs, we are also protecting ourselves. In general, though, all of the providers did very well in performing the speculum exams. I doubt if we need to do more training related to this. Lastly, all of the clients were informed about the outcome of the pelvic examinations.

Did the provider encourage the patient to discuss the results of the examination with her spouse or partner? Out of the forty-two cases, this occurred only in twelve cases.

The length of consultation time, ranged from five to fifty minutes with an average of 22 minutes for new patients. For follow-up and re-visit patients, the length ranged from 4 to 95 minutes with an average time of 14 minutes. From these numbers we see that the new clients were being consulted a little bit longer than those who were there for a follow-up. This is very understandable, as new clients have more needs. You need to talk to them for a longer time and examine them more closely.

That is about all of the results that we found. I hope that this report would serve as an eye-opener for all of us so that we could all improve the quality of care that we are giving our clients. Thank you very much. 


\section{OPEN FORUM}

Dr. Marilou P. Costello, PopCouncil: This is not really a question. I would just like to put into context all the things that we have been discussing this morning. Before moving into the discussion on the management of RTIs in greater detail, we thought that it would be important for the participants to have a general idea of how this phenomenon of RTI is perceived by the community as well as to get a better understanding of the health-seeking behavior of members of the community that you are working in, so that you will be able to serve them better in your health centers. We started with some general background information and we will continue to do that for much of this morning before going into the specifics of actual service delivery issues. This type of information is often discussed among NGOs and among women's health advocates when they hold meetings like this, but I think that it is a very good opportunity for our own service providers to also be aware of these research findings.

Dr. Ruth Leoncio, DOH: I would just like to clarify something. One of the results that you cited concerned the different family planning methods that the health clinics offered. How exactly did you come up with those figures?

Dr. Jesus C. Encena: We asked them to list the different methods that they offered in the clinics. We also compared their answers to the available service statistics.

Dr. Ruth Leoncio, That is what confuses me because, as far as I know, only the LGUs have service providers' training for NFP and STD services. 
Dr. Marilou P. Costello: As a matter of fact, I brought this up with Jess last night. I was saying that I have not noticed much activity going on in terms of training on LAM, yet why are we finding that all of the seven clinics say they are providing LAM? This is a mystery to me. Secondly, I know that we are still trying to pilot test the integration of NFP within the FP centers and yet we still have all seven centers saying that they offer NFP services. I would like to call the attention of Joji who is in charge of management information systems. Maybe they can talk about NFP in a general sense, or what LAM is, but in terms of actually helping, explaining and instructing the client on these methods, we are not sure whether this is actually happening. They might be reporting that the service is available, but it is not in reality.

I also want to clarify another issue. Earlier, you said that in four clinics there is a separate client record for RTI cases. Later, however, you said that there are no service statistics for RTI cases in the health centers. What do you mean by this? Doesn't this seem like a contradiction?

Dr. Jesus C. Encena: In the FP program, the health centers have twelve monthly reports on the service statistics for the FP methods that were provided. The RTIs are not included in these reports. The RTI records are just kept for the sake of future reference and treatment. They don't keep these records for statistical purposes.

Dr. Jocelyn Ilagan, DOH-FPS: Maybe what Jess was trying to describe is the FHSIS recording system. We have yet to incorporate RTIs in the statistics. What we have, however, are the client records. These are being maintained at the health facilities. While we report cases of STD/AIDS, we have not yet made allowance for reporting RTIs in FP cases under the FHSIS. We will, however, be incorporating this for the first time. 
Dr. Yolanda Condenuevo, Quezon City: What about vaginal discharge? This was classified under STDs and not RTIs.

Dr. Jesus C. Encena: There is actually a new reporting form for STDs. I have seen a new form for reporting vaginal discharge for the syndromic management. I hope to show you these forms soon.

Dr. Jocelyn Ilagan: You mentioned the results pertaining to the total time of consultation. Did the figures include the counseling time?

Dr. Jesus C. Encena: Yes. The figures included everything. Not that much counseling was done for the follow-up and re-visits. At times, all the patient did was to enter the clinic and ask for pills. A visit could therefore take as short as just four minutes.

Dr. Marilou P. Costello: This is not so much a question as a brief clarification why we are interested in whether the provider encouraged the patient to discuss the results of the consultation with her spouse. We want to encourage both partners to be involved in family planning, particularly the husbands. Secondly, I would like to tell you about what we are doing in Davao City. Part of our intervention there is to improve the counseling of FP clients. In connection with this, I feel that the four-minute follow-up sessions need to be improved upon. We are trying to encourage contact between provider and client, including those who are coming for re-supply. What often happens is that, since the client is “just a re-supply person”, the provider doesn't even greet the client or ask if she is still satisfied with the method that she is using. These sorts of questions are very important to ask. We are trying now to upgrade counseling services and we hope that the service providers realize the importance of these issues, since these are a very essential component of the services that you are giving. 
Josefa Paurom, RHM, Jasaan: In our own set-up, we have five districts under our health center. If we want to be good service providers attention, there should be a one-to-one correspondence between the health centers and the districts. If this would be made possible, counseling could be carried out well. In our health center, we have so many programs to attend to that we are not able to give special attention to any specific program. I know that this sounds very idealistic, but if we could only find a way to afford one FP center per area, we could give better service.

Dr. Marilou P. Costello: I don't know if Joji would want to respond to this. I think that this is an issue that we are all very aware of. I think what Ping is really saying is that, ideally, our services will improve if there is someone who specializes solely in FP. On the other hand, there is also the reality that this is not possible in some of the LGUs because of limited resources. Yet I think that the concept is not as difficult and as taxing as you might think it is. We are not just talking strictly about counseling, but even just a simple, "How are you?" is not very difficult to do. This is not very expensive or timeconsuming to do, and it can make a definite difference. It would probably only take an extra minute or two to mention some concerns and to ask some additional questions.

Dr. Ruth Leoncio, DOH: I think that it is just a matter of proposing to your LGU if it would be possible for you to have one service provider assigned especially to FP services. We are training a lot of service providers to make these services very accessible to our clients.

Dr. Marilou P. Costello: No one is saying that you must give perfect service, but we are saying that you should give good service. Suppose there is a mother with so many children. If she sees one of her kids holding a knife while another 
starts to cry, is she going to ignore the one holding the knife because the other one is crying? In the same manner, Ifeel that it is a basic requirement for us to provide good service. This should be a given. It should be basic for us to wash our hands before giving a pelvic examination. If we are not able to give good service, we are just adding to the problem, not solving it. This is the perspective of quality of care. We are saying that, if you are committed already to providing service, you might as well provide good service. 


\title{
PRESENTATION OF SITUATION ANALYSIS RESULTS (II)
}

(Staff Interview and Client Exit Interview)

\author{
Ms. Carmeli Marie Chaves \\ Research Associate \\ The Population Council
}

The situation analysis which we conducted also involved interviews with clinic personnel. All in all, we interviewed 22 service providers. These consisted of five physicians, seven nurses, eight midwives, and two population program officers. Most of these we found to have long been providing reproductive health and family planning services, even if not always with their current health center. Thirty-two percent of the respondents have been providing FP services for five to nine years and twenty-three percent have been doing this for fifteen to seventeen years. As for training, eighty-two percent of the personnel have taken the FP basic/compre. Seventy-three percent have been trained on DMPA and IEC, while sixty-eight percent have received training on interpersonal skills and fifty-five percent on STD/HIV/AIDS. Only about twenty-seven percent, however, have received training on syndromic management. Other training related to reproductive health that the respondents took were Copper-T IUD insertion, pill dispensing, and Contraceptive Delivery and Logistics Management Information System (CDLMIS). A few were trained in gender sensitivity, counseling in voluntary surgical contraception, and community organizing.

When asked whether their past training had sufficiently prepared them to address FP method side effects, the responses were almost equally divided. Fifty-five percent said "yes" and forty-five percent said "no". Those who gave the latter response generally felt they lacked the training to deal with medical complications.

When asked if they had heard about reproductive tract infections, twenty respondents, or ninety-one percent, replied that they had, while two respondents had not. In spite of this, however, seventeen respondents said that they had not received training on 
managing RTIs. Three said they had received training, but two of these believed that their training was insufficient to enable them to address the RTI cases that may be found in the health center.

The providers were also asked what they would say to a client who would seek diagnosis and treatment of an RTI in a health center that did not offer those services. About ninety-five percent said that they would refer the client to another clinic or service delivery point such as a government hospital, STD clinic, or another RHU. About nine percent said that they would suggest a mode of RTI management while one respondent said she would recommend a pap smear.

Sixty-eight percent of the respondents said that they had attended to an RTI case in the past, while the remainder had not. Most of the cases cited were vaginitis, cervical erosion, cervicitis, moniliasis, gonorrhea, and trichomoniasis. Usually these were detected during IUD check-up/insertions and pap smears. As for the number of RTI cases reported, a third of the service providers said that they saw 1-2 cases per month, a fifth said they saw 3-4 per month, about one-tenth said they saw 5-6 in a month, and another fifth said that they encountered 1-3 per year. The remaining tenth said that they saw about 4-6 cases per year. Almost ninety percent of these cases were treated with antibiotics or suppositories. The rest were either referred to another health center or provider, or counseled and given advice on hygiene and condom use.

All providers except one agreed that clinic personnel should be trained in RTI management. The lone respondent who disagreed justified his answer by saying that there was no need for nurses and midwives to train in RTI management since a doctor would be present in the clinic anyway.

While seventy-seven percent of the respondents said that they did not believe that using FP methods increased the risk of acquiring RTIs, twenty-three percent believed so, citing methods such as the IUD and pills. All of the service providers mentioned sex with an 
infected partner as a mode of transmission of RTI. The other modes of transmission that were mentioned included lack of personal hygiene (50\%), unclean water or surroundings (50\%), unsafe abortions or IUD insertions (5\%), and an overgrowth of organisms in the reproductive tract $(5 \%)$.

When asked if pills provide protection against STDs, seventy-three percent disagreed, while the balance either agreed or said that they were not sure. All the respondents, however, said that condoms did give protection against STDs.

The most common RTI-related complaints/symptoms mentioned by the providers included vaginal discharge, urethral discharge (in men), lower abdominal pain (in women), genital ulcers or sores, scrotal swelling, painful urination, fever, and painful intercourse. When asked what type of vaginal discharge was abnormal, eighty-two percent of the providers said yellowish or greenish discharge was abnormal. A big majority also felt that foul-smelling, thick and itchy discharge could be considered unusual. Also mentioned were pus-like, cheese-like, blood-streaked, and frothy discharges. Half of the respondents said that urethral discharge was a sure sign of an RTI, twenty-three disagreed, while twenty-seven percent said that they were not sure.

The respondents were also asked about their perceptions of the specific roles of the doctor, nurse, midwife and PPOs in RTI case management. The doctor was perceived as the one in charge of diagnosis, treatment, health teaching and counseling, as well as drug prescription. The nurse receives complaints, examines clients, detects RTI symptoms, does history taking, performs health teaching and counseling, explains medication to the client, and follows up the treatment given by the doctor. The midwife and the PPO were also perceived as routinely doing urinalyses and pap smears, and suggesting FP methods appropriate to the clients.

The service providers were also asked if they thought non-doctors, particularly nurses, midwives, and PPOs, should be allowed to provide treatment after having been trained in RTI 
case management. Twenty-three percent said yes, especially those working in clinics in farflung barangays. More than a half, however, said that it depended on the situation. They felt that non-doctors should not be allowed to dispense drugs without a standing order from the $\mathrm{MHO}$, and that this should only be done with the doctor's supervision and in severe or emergency cases. Four persons, or eighteen percent, said non-doctors should not be allowed to treat or prescribe drugs under any circumstances.

Suggestions for improving services at the health center were also advanced by the respondents. With regard to facilities and equipment, a separate FP office with its own comfort room was suggested because the clients apparently had to go out of the exam room in order to wash. There were also requests for more FP equipment. Suggestions related to the staffing of the health centers included the hiring of more nurses and midwives as well as a permanent medical technologist and a PPO for each clinic. More materials on FP and the prevention of infections were recommended. In addition, it was recommended that more time be given for the counseling sessions and that the husband also be included. As for service provision, it was suggested that the treatment should be coupled with free medicines; laboratory services should be offered daily; auditory privacy should be maintained; and that the FP providers should handle only one program each. It was also recommended that a referral system in tertiary centers be developed, as well as a system for recording transient clients. Other suggestions were that adequate referral forms and individual records for RTIs be kept and that an information drive on RTI/STDs be conducted.

The fourth part of the SA was the client exit interview. Thirty-eight clients were interviewed, all of whom were females. Their main reason for coming to the health center that day was to seek FP services. Under this, DMPA injections accounted for $26 \%$, pill resupply $24 \%$, IUD check-up $13 \%$, and IUD insertion 5.5\%. About ten percent of the clients also came to ask some questions about FP methods. In addition, sixteen percent came to have their child immunized. Ninety-two percent said that they had received the services they wanted, two clients said that they had not, and one said that she had received some service, although it was not enough. One client who said that she had not received the service that 
she wanted said that this was because she had missed her menstruation and was therefore not given pills. Instead, she was asked if her husband would consider using condoms. The other woman had come for a DMPA injection but the center had run out of vials of DMPA, so she was told to return.

When asked about the length of the consultation, sixty-three percent of the FP clients said that this was about right, while the rest said that it was too short. Sixty-one percent said that they had asked at least one question about FP, during the consultation, with more than 90 percent of these saying that their questions had been answered satisfactorily. All respondents said that the provider was easy to understand.

Seventy-one percent of the clients were satisfied with the auditory and visual privacy provided by the center, sixteen percent were not, and thirteen percent said they were not sure. In addition, all respondents said that the opening hours were convenient for them. When asked to estimate the waiting time between their time of arrival and the time that they received service, three clients said that they had to wait from thirty minutes to an hour. About half of the clients waited for less than thirty minutes, while forty-five percent of them said that they did not have to wait at all. Those who had waited felt that the waiting time was reasonable and ninety percent of them found a cool, comfortable waiting place in the health center.

The respondents were next asked about who had accompanied them to the health center. Fifty-five percent had come alone, thirteen percent had come with a friend or neighbor and about ten percent had come with their child/children. Only two had come with their spouse. Clients who had not been accompanied by their spouses were asked if their husbands would have come along that day if they had asked them to. Exactly fifty percent said yes, while the other fifty percent said no, saying that their husband had work, or was stationed in another place. 
With regard to the sex of the provider attending to them, a third of the clients had no sexual preference, while two thirds said they preferred female providers.. In addition to this, clients were asked about other characteristics that they preferred in the service providers. It is interesting that the highest ranking characteristic was not skill but that the provider be accommodating and gentle. Clients also wanted a provider who was respectful and gave equal treatment to all the clients. Other characteristics like being patient, not strict, calm, and a sympathetic listener were mentioned, too. Two respondents wanted a provider whom they knew personally and only one wanted a skillful and confident provider. It is thus evident that these women put greater emphasis on interpersonal skills than on medical knowhow.

Most of the clients said that they were satisfied with the service given to them and that the service had been given in a short time. The clients were happy that FP personnel were generally friendly, that the service was free, and that the clinic appeared to be clean.

When asked to give suggestions on improving service delivery, most respondents said that they wanted equal treatment for everyone, regardless of age, social status, gravity of the illness, or occupation. The provision of free medicines was also suggested. The clients also requested for a more accommodating staff who did not rush the service.

Seventy-one percent of the respondents said that they had heard of STDs/ RTIs. Of those who knew about this, seventy-eight percent said they would feel comfortable talking with a service provider about these illnesses. In comparison, about twenty percent said that they would not be comfortable because of embarrassment while three percent gave no answer.

The socio-demographic information that was obtained provides a profile of the clients. The majority of clients fall within the age group of 20-34 years old, with an average age of 28.8 years. The majority have finished high school, and ninety-two percent can read 
a simple message without difficulty. Eighty-four percent of the clients were not employed at that time of the survey. Of these, sixty-six percent do not contribute to the family's income in any way. As for religion, the majority were Roman Catholic.

So, as you can see, there is a mixture of "good news" and "not-so-good" news from these data. Overall, the FP clinics are doing a reasonably good job but there is still room for improvement, particularly with regard to the integration of RTIs within the FP/MCH programs. 


\title{
OVERVIEW OF REPRODUCTIVE TRACT INFECTIONS
}

\author{
Dr. Jesus C. Encena \\ OR Country Fellow \\ The Population Council
}

What are Reproductive Tract Infections (RTIs)? As the name indicates, these are infections of the reproductive tract, which is found in the pelvic area. Reproductive Tract Infections are sometimes called Genital Tract Infections (GTIs) or Sexually Transmitted Diseases (STDs). Strictly speaking, though, RTIs can include STDs, endogenous infections and iatrogenic infections. Not all STDs are RTIs; conversely, not all RTIs are STDs. Sexually transmitted diseases are due to organisms that are transmitted through sexual contact, like gonorrhea, herpes, or syphilis. Endogenous infections are due to organisms that are normally found in the genital tract which become opportunistic infections, depending on the changes in the body, such as hormonal changes, or current diseases like diabetes. Iatrogenic infections are due to incorrect and unsafe medical procedures. For instance, a patient could contract an RTI because the service provider at the clinic did not use clean gloves when examining her.

As I said earlier, not all STDs are RTIs. In order to be classified as an RTI, the major manifestation of the disease should be in the genitalia. Hepatitis B is an STD, but you cannot see manifestations of this on the genitalia, so it is not classified as an RTI. On the other hand, there are also RTIs which are not STDs, such as bacterial vaginosis or candidiasis.

Reproductive tract infections are actually very common. The prevalence rate, however, differs from area to area, so the actual prevalence is difficult to know for sure. One problem is that we really can't identify which group of women are most in need of our attention and services. However, we can get information on RTIs from other places around the world. Sexually transmitted diseases are very common in Africa, where studies have shown that many of these infections are asymptomatic. In fact, it was found that $50-80 \%$ of these infections are asymptomatic. For people like us who work in FP services, we can do case finding among asymptomatic women. How do we go about this? First, we can have annual 
check-ups for all continuing FP users. Second, there should be strict compliance to Form 1 which says that every time there is a new acceptor, you must perform everything, from the bimanual exam to the speculum exam. Another way of finding cases arises when women voluntarily come to you and say that they have vaginal discharge that is itchy and foulsmelling.

As for treatment, the trend at present is toward syndromic management. In some instances, though, the patients do not reveal all the prominent symptoms such as vaginal discharge. There are also diagnostic and clinical problems. Results are variable and often contradictory. For instance, a speculum exam can reveal vaginal discharge that is yellow and frothy, which is indicative of trichomoniasis, but when you do a lab exam, you are not able to find evidence of trichomoniasis. This does not necessarily mean, however, that the patient does not have trichomoniasis. Even if you have laboratories, you cannot always expect to come up with positive results. Sometimes these tests have low levels of sensitivity.

Some of the major complications arising from RTIs include fetal death, low birth rate, and congenital infection. Congenital infections are particularly common when the mother's vaginal tract has candida and chlamydia. When the baby passes through the mother's tract, there is a great possibility that the baby will develop chlamydial pneumonia. Gonorrhea can also result in eye infections in babies.

Reproductive tract infections don't only infect the vaginal tract. They can also go up to the endometrium of the uterus, the fallopian tubes, and the ovaries, resulting into a more serious Pelvic Inflammatory Disease (PID). This can cause infertility by scarring the fallopian tubes. Scarring results in blockage, thereby rendering the patient infertile. In addition, PID can also cause death. You need to watch out for fever in the first 48 hours after delivery. Fever can be caused by postpartum sepsis or infection.

In Africa, RTIs constitute 50-80\% of the causes of infertility in women. In Asia, the numbers are around $15-40 \%$. What, therefore, is the impact of RTIs on FP service? One 
possibility is that RTIs may decrease the demand for contraception. When the RTI is perceived as a side effect of the contraceptive method being used, this will result in the discontinuation of the use of this contraceptive. Real or perceived association between RTIs and a certain FP method may result in client or provider bias against that method.

What are the determinants that increase the likelihood of a woman getting RTIs? First we must consider the microbiological flora. While there are organisms that are normally present in the vagina, hormones or illnesses such as diabetes can cause changes in the vaginal flora, thereby creating an infection. Secondly, any changes in the vaginal $\mathrm{pH}$ can also render a woman more susceptible to RTIs. Third, the possibility of RTI co-infection should also be taken into account. If a client has trichomoniasis, for example, it is very likely that she will get other RTIs. Hormonal changes also occur during a menstrual cycle or during pregnancy, causing vaginal itching and discharge. Opportunistic infections, HIV infections and prior RTI exposure are other determinants, including steroid use. The patient's personal environment should also be considered, such as her sexual behavior. The earlier a person is initiated into sex, the greater the chances of being exposed to RTIs. Sexual practices and health behaviors such as condom or pill use are also important. Pill use is associated with a lower incidence of PIDs. It is thought that the pills thicken the cervix, preventing organisms from entering the cervix. A related topic is circumcision. In areas where circumcision is not widely practiced, there is a higher incidence of herpes. This, in turn, raises the incidence of cervical cancer, because when the penis is dirty, the chances of contracting an RTI increase.

Macroenvironmental factors also affect the likelihood of a person getting an RTI. Poverty and the status of women are some examples. For instance, women in Africa often go untreated as they are expected to suffer in silence. Also to be taken into account is the political and public health infrastructure, as war or political unrest could change the priories of the government. Lastly, technology is also a factor. The more advanced the technology of a country, the better the diagnostic and preventive services will be, thereby lowering the incidence of RTIs and allowing for their better management. 
We have three levels of intervention for the prevention and treatment of RTIs. First is the primary intervention, when patients have not yet contracted an RTI. If our goal is to prevent STDs, we should work towards delaying the age of first intercourse, and reducing the number of sexual partners. Condom use should be promoted and the incidence of nonconsensual sex or rape will have to be reduced. Endogenous infections can be avoided by practicing good hygiene. Prevention of iatrogenic infections falls mainly in the hands of us health care providers. We must always follow proper infection prevention practices such as the sterilization of speculums, gloves and other laboratory instruments. We must also improve quality of care, especially technical competence.

The second level is identification of the organisms and treatment of established infections. We have to properly manage symptomatic infections. There is also a need to screen for asymptomatic women. Right now, some areas of the world are considering the efficacy of a mass treatment approach. For example, all women in a certain area will be treated for some infection that is commonly found there. This idea is still being evaluated, though, because of the potential cost and the possible emergence of resistant strains.

Third, we need to minimize complications. This level is quite costly since it requires a number of things. It is very difficult to lobby for improved management of septic abortions in the Philippines because of the religious issues it will raise. Procedures for dealing with lifethreatening situations such as ectopic pregnancies should also be improved, as well as management of infertility. Screening for cervical cancer through pap smears is important. In addition, the early identification and treatment of pregnant women with syphilis should be a primary consideration. As you know, if a pregnant woman has syphilis, there is a good chance that she will give birth to a congenitally malformed baby. Lastly, we must also find some way to improve post-partum services for early detection and treatment. 


\title{
HISTORY TAKING, PHYSICAL EXAMINATION AND A REVIEW OF THE HUMAN REPRODUCTIVE ANATOMY
}

\author{
Dr. Erickson San Juan \\ STD/AIDS Program Coordinator \\ City Health Office, Cagayan de Oro City
}

Good afternoon, everyone. I have been asked to give a talk on history taking, as well as to review the male and female reproductive organs. As far as I am concerned, a major objective of this session is to convince the participants about the importance of obtaining an accurate history. A second goal is to re-learn the most important elements of an STD history.

History taking is indeed important because it plays an integral role in the diagnosis of the type of disease entity, be it an RTI or some other type of disease. Hence, accurate history taking is a must.

Second, if you are able to do a very detailed and complete history taking, you can come up with your own initial or working diagnosis. Once you have this, you will be saving money as well as time because you do not have to request for so many lab exams.

You have to remember that history taking with people infected with STDs or RTIs is quite different from history taking for patients with ordinary diseases. In cases pertaining to RTIs or STDs, you will need to ask very personal questions. Because of this, I suggest that you advise your patient ahead of time that you will be doing this and to obtain his or her consent.

How will you be able to get an accurate history? First and foremost, you must gain the trust of the client so that he/she will be able to open up and tell you about the symptoms that he/she has been feeling. Secondly, you should provide a private place for the 
consultation. Some clinics and social hygiene centers do not have a private counseling room. In the smaller health centers, you can just go outside, sit under a tree, and conduct the interview there. Third, you must be an understanding and sympathetic listener. The subject of STDs is a very delicate one, so we must be very tactful. Lastly, you should give the assurance of complete confidentiality. Inform them that the records are well-kept in a secure place. It is required of every FP clinic to have a filing cabinet with a lock for storing these types of records.

Here are some notes on history taking. First of all, get the name and address of the patient. In social hygiene clinics, it is acceptable to use false names, but in health centers, it's better to use real names. Otherwise, they may forget their false names and the health provider will have a hard time looking for the records.

Second, get the marital status of the patient. I would advise that you ask this only after the history taking has been completed. Why? For instance, if you ask the patient's marital status and the patient answers that he/she is married, and then the next question you will ask is the number of sexual partners the patient has had, the patient will probably hesitate to admit to having had several partners.

Third, you need to find out the age and the ethnic group. This is especially important for future studies to be done regarding RTIs and STDs.

Next, you need to find out about the present complaint of the patient. This is also very important because this is a basis for making an initial diagnosis. If the patient comes in and complains of vaginal discharge, you already have a clue for your initial diagnosis, because it would probably be trichomoniasis, gonorrhea, or chlamydia. Aside from just asking about vaginal discharge, however, you also need to get a general picture of the patient's health, such as whether or not he/she is feeling any other pains or symptoms. 
The date of last sexual intercourse is also important. If you can get this, as well as the date of the onset of symptoms, you can determine the incubation period. This can also help you in your diagnosis, because particular infections have particular incubation periods. Gonorrhea, for example, has an incubation period of 3-7 days, while chlamydia has an incubation period of 1-2 weeks. In addition to this, you should also try to get the patient's number of sexual partners. You all know by now that the greater the number of sexual partners, the greater is the risk of getting an RTI.

You also need to look into condom use. We all know that the condom is a protective apparatus against RTIs, so it is very important that we keep reminding our clients how to use condoms correctly and consistently. The importance of consistent condom use can be well illustrated in the example of commercial sex workers. If they are with customers, most use condoms. If they are with their boyfriends or husbands, however, they do not. What if their boyfriends or husbands have other partners? It is very important that we give detailed instructions to our clients on proper condom usage--from storage, consistent use, to disposal.

It is also important that you ask about previous STDs and RTIs. If you can elicit a history of recurring STDs, and your patient has an infertility problem, you can see that it is probably the history of STDs that is the cause for this.

Even seemingly harmless and unrelated factors may be involved. On example would be travel. For some people, the more they travel, the less inhibitions they have because they are far from their family and are alone. Some then tend to indulge in extramarital relationships.

You may also ask about any antibiotics that the patient has been taking. Some clients take prophylactics before having sex with commercial sex workers. In addition to this, you 
should elicit information as to any history of blood transfusions and injections. As we know, HIV or syphilis can be transmitted in this manner.

Lastly, you must try to get the date of the last menstrual period. Some service providers immediately assume that a patient has PID if the symptoms include lower abdominal pain and vaginal discharge and they fail to ask about the date of the last menstrual period. By not doing this you might fail to diagnose an ectopic pregnancy.

The final thing you have to do when taking the client's history is to come up with a clinical summary of all the information you have obtained.

Let's now move on to the procedures involved in the physical examination of clients. The first thing you should look for in female patients is vaginal discharge. Ask them about the color, the smell, and the amount. You must also ask when the discharge began after the date of her last sexual intercourse. Once you have this information, you can come up with an initial or working diagnosis. For example, you could have a patient who comes in with a yellowish or greenish discharge. This could either be gonorrhea or trichomoniasis, so the next question would be whether the discharge is frothy or not. If it is, you can rule out gonorrhea and conclude that it is probably trichomoniasis. Now you only need one lab exam to confirm your diagnosis.

The next symptom to look for is itchiness and redness. Which STDs or RTIs exhibit itchiness? Two of the most common would be candidiasis and trichomoniasis. When you conduct your physical examination, you will often be able to tell the difference between these two because you will usually see scratch marks on the external part of the client's genitalia if she has candidiasis. In trichomoniasis, however, the itchiness is usually concentrated on the internal parts of the vagina. In addition to this, you need to look for any type of rashes. An example of an STD which causes rashes is herpes genitalis. It usually starts with a vesicular lesion which ulcerates and eventually becomes a large wound. 
Pain or soreness is another important indicator. Females usually experience painful intercourse if they have vaginitis or cervicitis. You need to find out if the patient is experiencing dysuria or nocturia. Dysuria is painful urination, while nocturia is frequent urination, especially at night. These are both signs of urinary tract infections. It could also be indicative of an RTI that has ascended. You also need to ask about ulcers. If your patient does have ulcers, you need to find out if they are painful or not. Syphilis ulcers are painless, while ulcers caused by herpes usually are not. Next be on the look-out for lumps and swellings. Examine the groin and see if the lymph nodes are enlarged or swollen. People with RTIs usually have distended lymph nodes. Ask about any other pains that the patient has been experiencing. Abdominal pain could indicate PID or endometriosis. Joint pain, on the other hand, is a complication of gonorrheal and chlamydial infections.

Information about the patient's menstruation is important. Ask if the menstruation is regular or not. Is there spotting or bleeding after intercourse? If there is, you could possibly have a patient with cervical cancer or an infection of the cervix. Do not forget to ask if a cervical or pap smear has been done. Also ask if she uses a particular type of contraception. We don't recommend some types of contraceptives, such as IUDs, to commercial sex workers. In general, IUDs will make them more vulnerable to infection.

It is very important to treat male patients, even if very few of them get involved in family planning. If we treat only the females and their partners remain infected, the infections will keep coming back. We must treat both of them at the same time or else there will be what we call a "ping-pong" effect--the infections will keep coming back.

Urethral discharge is the most common symptom in a male who has an STD or an RTI. If you examine the urethra, you will see that it is inflamed and that the patient has urethritis. Just like in the physical examination of females, you need to characterize the type of discharge. If there is urethral discharge, you can immediately assume that the patient also 
has dysuria because the urethra is inflamed. In addition to this, you need to check for dyspareunia or pain during sexual intercourse. This could be due to urethritis.

It is important to check for ulcers on the penis, as well as lumps, swellings, rashes, or itchiness. In cases where itchiness is reported, you need to check the pubic area for rashes due to scabies or pubic lice.

Here are some other points to remember. First, many patients are afraid of STDs and their effects, so we must always remember to be very understanding. Second, many patients feel a great amount of guilt and shame. They fear being exposed, so it is essential that you discuss their case in a private place and inform them of the precautions you are taking to keep their files confidential. Third, while many STD symptoms can be unpleasant, what patients want and need most is effective treatment. In order to give this, you must tell the patient, "Trust me, you have to tell me everything so that I can give you the best care possible." Fourth, all patients need counseling as well as information about STD prevention in addition to the medical treatment that is required. You should always counsel your client to bring his/her partner to the clinic for treatment. Fifth, we should remember that people have sex throughout their lives, so STDs can occur at any age.

My last topic will be a review of the anatomy and physiology of the male and female organs. At the end of this session, you are expected to have a working knowledge of human genitalia and how they are affected by STDs. In addition to this, you should know the anatomical terms necessary to adequately manage the most common STDs and RTIs.

For the male genitalia, there is what we call the scrotal sac or the scrotum. Actually, this is the outer skin covering of the testis. This usually appears corrugated. If the penis becomes erect, the scrotum becomes smaller and the corrugations become more pronounced. Within this sac is the testis, which is responsible for the production of sperm. This is enclosed by a sheath-like organ called the epididymis. The epididymis is for the storage and 
maturation of sperm. Once the sperm is mature, it travels through the seminal vesicles to the vas deferens. This is therefore contained in your spermatic cord. Then it enters the external spermatic canal and it will go behind the urinary bladder to the seminal vesicles. This is the organ that is responsible for the production of semen. After this, the sperm will be ejected to the urethral part of the prostrate through the ejaculatory duct. The urethra is the passage leading out of the body. Males have an accessory gland called the Cowper's gland. This serves as a protective mechanism by neutralizing harmful aspects of the environment which are not good for the sperm. Then there is the glans penis. Here we see the frenulum which is the most sensitive part of the male reproductive system. The parts of the male reproductive system that are prone to STDs and RTIs are the urethra and the skin of the penis. You often find ulcers and blisters in the external parts of the penis.

Now for the female genitalia. First, there is the mons pubis, which is made up of fatty tissue covered with skin and pubic hair. Next, there are the labia major and the labia minor. The difference between the two is that the labia minor does not have hair and fat. The labia minor borders the vestibule. The urethral opening, paraurethral ducts, and the vaginal opening are parts of the vestibule. The paraurethral ducts don't serve much of a purpose. In fact, some doctors even cut these ducts as these make the woman more susceptible to infection, especially gonorrhea.

You should also be familiar with the female internal reproductive organs. The ovaries produce the ovum and the female hormones, particularly estrogen and progesterone. Ovarian and suspensory ligaments support the ovary so that it will not fall. Next there are the fallopian tubes which are about $9-10 \mathrm{~cm}$ long. These are divided into four parts. The first part is the interstitial which is imbedded in the uterus, followed by the isthmus and then the ampulla, which is the widest. Last, there is the fimbriae which is responsible for catching the ovum as it is released from the ovary. The primary function of the fallopian tubes is that fertilization takes place within them. After this, there is the uterus, which is the site of implantation. As Jess said earlier, if you have recurrent RTIs or STDs, there can be a lot of 
scarring that will occur, especially in the fallopian tubes. When this happens, the fertilized ovum cannot reach the uterus and it will become stuck in the fallopian tubes. This is what we call an ectopic pregnancy. Lastly, there is the cervix, which is divided into two parts, the endocervix and the ectocervix.

I hope this information will be of help to all of you. Thank you and good day. 


\section{OPEN FORUM}

Dr. Jesus C. Encena, PopCouncil: This is just a minor comment on the topic which we took up earlier: history taking. I noticed that the guidelines given by Dr. San Juan were quite detailed. Since most of us are mainly dealing with FP patients here, we might not need to ask for all these details all the time. I therefore believe that we should try to make an intelligent judgement as to whether it would be appropriate to ask all the questions, depending on the patient's condition.

Dr. Marilou P. Costello, PopCouncil: I would like to follow up what Jess has just said. I really like the thorough presentation of Dr. San Juan and I think that it is very important that we keep in mind all that he has said. For the purposes of the research, I think that it is high time for us to start thinking more about the issues he has just brought out. We need to evaluate which of these would apply to our regular FP or MCH clients. I agree with Jess when he says that you need to think in terms of your regular clients. I would therefore like to suggest that one activity that we can do is to group ourselves and come up with a set of questions that would fit the profile of your regular or "normal" clients.

Judith Clarin, Lapasan Health Center, Cagayan de Oro: Usually, when a patient comes in with an RTI, there are already complications. In this case, should we still proceed with a detailed history?

Dr. Erickson San Juan, City health Office, Cagayan de Oro: Definitely. You should always do this because it is only by taking a good history that you can get good information. This would bring you closer to the final diagnosis. 
Dr. Jesus C. Encena: Even if the chief complaint of the patient will already lead you to a diagnosis, it is still very important that you ask detailed questions, as this can provide information that could affect the management of the patient. Even if the discharge characteristics lead you to conclude that it is gonorrhea, you still need to ask questions on topics such as any allergies the patient has because this will determine the type of drugs you will prescribe.

Dr. Marilou P. Costello: We thought that the group received a lot of inputs during this interaction, and we feel that it is about time that we solicit your participation in return. We therefore asked a resource person from Xavier University, Professor Lita Sealza, to inform you about the group activity that has been planned on history taking.

Prof. Lita Sealza, Xavier University, Cagayan de Oro: We prepared a four-page draft of the clinical history record based specifically on the lecture of Dr. San Juan. We want you to provide us with a critique of this and to give us suggestions as to which questions should be asked and which indicators should be included, putting into consideration our FP or MCH clients. We will be giving you a copy of the draft before you leave. Each group will have five minutes tomorrow morning to present their comments on the draft.

Dr. Jocelyn Ilagan, DOH-FPS: I would like to make a final comment before everyone leaves. Since we are addressing RTIs in the context of FP, we should not forget about the husband. The women are not the only ones involved here. When we do research, we should always address two persons, not only one. This type of treatment or management is essential. Maybe when you do the activity this evening, you can also include the husband's concerns. 


\title{
REPRODUCTIVE TRACT INFECTIONS Causes of Genital Discharges and Ulcers
}

\author{
Dr. Ilya Abellanosa \\ Social Hygiene Clinic \\ City Health Office, Cebu City
}

Good morning. Yesterday, Dr. San Juan discussed the first part of RTI management: history taking. This is important primarily because by knowing the clinical history of the patient, you can come up with a presumptive diagnosis. Today I will be talking more about the different types of RTIs and their symptoms.

I would like to begin this morning with the causes of vaginal discharge. Most women blame their RTI symptoms on their nearing menstrual period because they don't want to accept the fact that they can have an RTI. They look for some sort of excuse because they do not want to deal with the possibility that they may have acquired an RTI. Thus, they tell themselves that their discharge is part of their menstrual cycle. The ovulatory cascade is a physiological cause of vaginal discharge. After women have their menstruation, they go through a dry period which is followed by ovulation, after which comes a wet period. Pregnancy also causes discharge, and so does the use of some oral contraceptives. Physiological vaginal discharge is characterized by a light brown stain which is neither odorous nor itchy. It is not accompanied by vulvar soreness and when you examine the discharge, it contains few polymorphic leukocytes.

In contrast to the physiological discharges, there are pathological discharges. You will usually know if it is pathological in nature when there is any change in quantity (it will increase), consistency, color, as well as the odor. Usually, if there is an infection, the discharge has an offensive odor and may be accompanied by itchiness, irritation, or a burning sensation upon urination. It may also be accompanied by lower abdominal pain, irregular menstrual periods, and painful intercourse. Vaginitis or cervicitis can cause abnormal vaginal discharge. Vaginitis can be due to candidiasis or trichomoniasis or bacterial vaginosis. 
Cervicitis is caused by gonorrhea and chlamydia. Aside from these infections, vaginal discharges can also be caused by the introduction of foreign bodies, such as condoms that were left inside the vaginal canal, tampons, or IUDs. Pathological discharges are often characterized by the appearance of pus or blood, usually with an offensive odor. Abnormal vaginal discharges can also result from chemicals such as those in cases of repeated douching. A lot of private doctors still advocate the practice of douching, and the women in the social hygiene clinics like to do this because sometimes it can produce negative test results for RTIs and they do not have to buy medicine. Some women use almost anything, from shampoo, laundry soap, or even toothpaste to clean themselves. This could result into an allergic reaction and be the cause of the discharges.

Why do you think there is a move now to integrate RTI management into Family Planning? Isn't the slogan of the DOH, "Health for All in 2000?" If someone goes to the health center with symptoms of an RTI, we do not have to refer them to the social hygiene clinic, because this would be a missed opportunity for us to integrate RTI service within FP. In Cebu, for example, only the social hygiene clinics handle the STDs. Because of this, if someone with an STD comes to a health clinic, he or she would not be treated, but referred to the social hygiene clinic instead. The problem, though, is that only about one out of ten people who have been referred to the social hygiene clinics actually go there.. Some complain that it is too far, others say that they are embarrassed to be associated with commercial sex workers, and the like. What we would like to happen is that you at the health clinics will be able to treat the RTI/STD patients yourselves. If this plan would succeed and the LGUs would be able to afford the medications, the health clinics will already be able to give treatment at their own level. After this training, you will all be given the standard treatment plans for the different RTIs so that you will not have to debate on which medication to give. There will be a list of medicines you will prescribe for each specific case, whether it be gonorrhea or chlamydia, or any other RTI. If the patient is pregnant, there will also be another set of medicines for her. 
I will stop here because I would like to spend the rest of the time in a discussion with you about the issues I have just brought up. I know that many of you have your own opinions on this matter and I would very much like to hear them. After the open forum, I would like to divide you into four groups and assign a specific RTI to each group for discusion and reporting. I will explain more about this later. 


\section{OPEN FORUM}

Odette Escorpiso, Bernardo Health Center, Quezon City: When I discover during the speculum exam that a patient has vaginal discharge, I call in the doctor to continue the consultation. In this case, it is the doctor who prescribes medicine for the patient. If there is no doctor available, I refer the client to the social hygiene clinic which is located adjacent to our health center.

Dr. Marilou P. Costello, PopCouncil: I do not know if Odette is referring to the health center in Quezon City with an STD clinic right above it, on the second floor of the building. When I was talking to the staff there, they said that FP clients usually get embarrassed to go up to the second floor because they might be labeled as a sex worker. Clients were requesting that they be given another entrance into the place. My point is this: I know that it is often more convenient for us to pass this sort of clients on to the social hygiene clinics, but we need to think a little bit more about doing this. We may not be aware of how they are really feeling. Many might have serious reservations about going to the social hygiene clinics.

Dr. Ilya Abellanosa, City Health Office, Cebu City: Ideally, after this training, all of you should be equipped to handle various RTIs. In such a case, you will not have to refer the clients to the SHCs since you will be able to treat them yourselves. I would like to ask the group if they have any apprehensions about letting people other than the doctors give medication? I know that in the Situation Analysis some doctors were against this idea.

Dr. Anacleto Awiten, Tagoloan Health Center, Cagayan de Oro City: I will allow the nurses to give medicines, provided they have undergone extensive training in RTI management. I will have to observe them first, and when I see that they know what they are doing, I will allow them to give medicines at their own discretion. 
Bernadette Sabio, Lapasan Health Center, Cagayan de Oro: In the case of the City Health Office of Cagayan de Oro, the medical officers go to the clinic only a few times each week. Dr. Zamora is our physician and I would like to know if we would be allowed to treat RTI patients in her absence.

Dr. Melodee Zamora, Lapasan Health Center: Since I go to the health center only once weekly, I think it would be okay for other health workers to handle RTI cases when I am not available, as long as they have had the proper training. We will have to face the possibility of something happening to the client, however. In case something like that happens, it will be the medical officer who would be blamed. Anyway, I think that this training will make it possible for the nurses to be given a list of the medicines that the doctors prescribe. In this way, we can ensure that the medication that the nurses prescribe would be the same as what the doctors normally prescribe.

I would also like to bring up another issue. In Cebu City, we have noticed that if a health center offers RTI services, there is a possibility that commercial sex workers would start going to that clinic for treatment. I would like to know if there is any apprehension that maybe the mothers would not go to the clinics anymore for fear of being associated with the sex workers?

Odette Escorpio, Bernardo Health Center, Q.C.: This is precisely the problem that we are facing now. Many of our mothers and FP clients have stopped coming to the health center because they think that we are using the same instruments for the sex workers and the FP clients. We are losing FP clients because of this.

Dr. Ilya Abellanosa: Actually this should not be the case if you are able to explain to your patients that you are taking the universal health precautions of sterilization. 
Besides, it doesn't necessarily mean that FP clients cannot be infected with RTIs. You can't just say that if a client is an FP client, you don't need to use gloves or sterilize the speculum after use. You need to treat every specimen as if it were contaminated.

Odette Escorpio: I think that what we must do so that the family planning clients will not worry is to reserve another set of instruments for commercial sex workers.

Dr. Ilya Abellanosa: You really don't need to do that. What would be best is to use a different set of instruments for every client. If this is not possible, sterilization can still prevent any contamination. In addition to this, how will the health workers be able to tell if the clients are sex workers or not? Many sex workers go to the health centers and not just the social hygiene clinics. Can you honestly tell if they are sex workers? I doubt that they introduce themselves as such.

Odette Escorpio: We can tell because we actually have a specific schedule during the day for sex workers.

Dr. Ilya Abellanosa: The people at the health center could not possibly know all the sex workers individually. What if these women live near the health centers? They would be able to go there anytime.

Dr. Anacleto Awiten: For me, I don't really have a problem with treating sex workers. The problem lies in some people who are less educated, especially those in the rural areas. They believe that they can get contaminated with STDs.

Dr. Ilya Abellanosa: Isn't it part of our job to give proper health education to our clients? You should find some way to ease these unfounded apprehensions. Educate your patients about the fact that as long as the universal health precautions are taken, they have nothing to fear. 
Yolanda Condenuevo, Toro Hills Center, Q.C.: In my opinion, the FP clients and the sex workers should not be separated. There is no need for the FP clients to get worried. When we go to a private doctor, for example, we wouldn't know if the speculum being used on us has been used on a woman with an RTI.

Odette Escorpio: In a rural area, the stigma is very strong. We need to consider the socio-cultural factors of this situation. Of course we would not want to discriminate against people, but we might have to do that in order for us to be successful. Maybe it would just be better for us to place the STD patients in one area and the FP clients in another.

Dr. Ilya Abellanosa: This is precisely what we are trying to undo. No patient announces if she is a sex worker or not. They just ask for your service and you should treat them equally. It does not necessarily mean that you are a sex worker if you have an STD. You can be a respectable housewife, but if your husband has multiple partners, you can be the one who will catch the STD. We should just explain to them that the speculum is sterilized after each use.

Odette Escorpio: I I agree with you when you say that we have to sterilize the speculum. I am not saying that we will select the patients that we will treat. All I was suggesting was to separate the equipment used on the patients with RTIs from the normal ones.

Dr. Ilya Abellanosa: What do you mean when you say the "normal" cases?

Odette Escorpio: Once a patient comes to us with a vaginal discharge, we know that there is a good chance that she has an RTI. All you have to do is to separate the equipment that will be used on her from those which will be used on those without discharges. 
Dr. Ilya Abellanosa: The problem is that more than 50\% of RTI cases are asymptomatic, so you will not always know for sure whether the patient has an RTI or not if you just check for discharges. In this case, all we can and should do is to sterilize all the instruments after each use. It should not matter if your patients are educated or not. Both sex workers and FP clients should be treated in the same way.

Dr. Belen Ligo: I have a comment. This is in relation to what Dr. Marilou Costello said about the health center in Quezon City. Since people are embarrassed to be seen in a Social Hygiene Clinic, I would suggest that we would rename it as a Reproductive Health Care Clinic, accepting both men and women.

Dr. Ilya Abellanosa: That is a good suggestion, but I think that the main thing we are discussing today deals with the fact that we should not, in any way, segregate sex workers from our regular clients. It is not fair. Even if the SHC is right beside the health center, we should treat them right then and there at the health center. We should not refer them to the SHC. I am not saying that you should be the one to treat all the sex workers. All I am saying is that, if a sex worker comes to you for treatment, she should be able to get that treatment right away, without having to be referred somewhere else.

If I might, I would now like to explain the activity which I have prepared for you. Group 1 will handle Gonorrhea, Group 2, Trichomoniasis, Group 3, Syphilis, and Group 4, Herpes. I want each group to give a report on these RTIs. The report should include the causative agents, mode of transmission, common signs and symptoms, complications, laboratory methods used for diagnosis, prevention and treatment, and family planning considerations. I would ask, however, that you only use your stock knowledge for this report so you should not use the notes that you have taken. 
(Group Reports)

\section{Group 1: Gonorrhea}

\section{Laboratory methods used for diagnosis: gram stain}

Prevention: Since about $80 \%$ of women are asymptomatic, it is usually the men who first discover the symptoms. Once the partner has been diagnosed, any sexual contact should be avoided. If the diagnosis is not certain, then the use of a condom is strongly recommended. Patients should be encouraged to seek immediate treatment.

Treatment: The treatment of choice is Cefixime, $200 \mathrm{mg}$ per capsule, 2 caps in a single dose. Pregnant women take Erythromycin, $500 \mathrm{mg}, 4 \mathrm{x}$ a day for 7 days. For neonates, use Ceftriaxone, $50 \mathrm{mg}$ per $\mathrm{kg}$ body weight, deep IM injection.

FP considerations: About $80 \%$ of women are asymptomatic, so before any FP method is given, we must make sure that there is no infection. Condom use is also advisable.

\section{Group 2: Trichomoniasis}

Causative agent: Trichomoniasis vaginalis is a flagellated protozoa which causes infections of the vagina and the cervix, and, occasionally, the prostrate and urethra of the male.

Mode of Transmission: It is transmitted through sexual intercourse as well as through urethral and vaginal discharge.

Common Signs and Symptoms: This disease is often asymptomatic. For those with symptoms, there is usually a frothy, yellow-greenish, foul-smelling discharge. In women, it is also characterized by itchiness of the vulva and the vagina. In men, it is characterized by itchiness of the urethral opening.

Complications: These include PID and infertility.

Lab test for diagnosis: Wet mount

Prevention: Abstinence from sexual contact while under treatment

Treatment: Metronidazole $500 \mathrm{mg}$, one tablet twice a day for 14 days. The amount of $2 \mathrm{~g}$ can also be given in a single dose. After this, vaginal suppositories once a day for a week.

FP Considerations: For IUD users, we should advise the removal of the IUD, as well as the constant use of condoms. 


\section{(Dr. Abellanosa resumes her lecture.)}

There are other causes of vaginal discharge that the groups will not discuss here. One of these causative organisms is Candida albicans. This is common among FP clients. In addition, people who are diabetic are also prone to this, so it is important that you are able to get a good history. If they are diabetic, the diabetes should be treated first. People who also commonly get candidiasis are people with AIDS, people with poor anal and perianal hygiene, and pregnant women.

The main clinical manifestation is vaginal discharge. Through a pelvic exam, you can already identify the white, curdy discharge produced by Monilia. Another common manifestation is itchiness. If you examine the vulva there is also a possibility that there will be pus because of constant scratching. This could also cause dysuria and dyspareunia.

Laboratory diagnosis is made easy with the $\mathrm{KOH}$ examination. Treatment and prevention include the practice of good personal hygiene and a search for predisposing factors. Medication is the suppository Clotrimazole (200 mg) for three days. After this, Miconazole (400 mg) should be used for three nights. Anti-fungal medications such as Ketoconazole and Itraconazole can also be used.

We also have a new drug called Diflucan. This can be taken in a single dose only. It is a little more expensive, though-- about P100 per capsule.

Aside from Candidiasis, there is Bacterial vaginosis. This is not caused by a single

agent. Several of the causative agents are actually normal vaginal flora which multiplied because of a change in the $\mathrm{pH}$ of the vagina, causing the infection. 
A most common symptom is foul-smelling discharge, often described as having a "fishy" odor. It is usually grayish and sticky, sometimes even adhering to the mucosal wall of the vagina. Even though it seems like a relatively simple infection, it can lead to PID and infertility. In pregnant women, it can cause the premature rupture of the membrane. Because of this, it must be treated immediately.

Diagnosis is carried out through an examination of the discharge and the determination of the vaginal $\mathrm{pH}$. By using NSS, you will be able to identify the presence of "clue cells". Dr. Encena will discuss the lab exams used for this. Treatment is the same as that for Trichomoniasis.

So these are the infections that cause cervicitis. Let me just add that gonorrhea is not only manifested in the genitalia. You can also find anal discharges. In addition to this, gonorrhea can also be manifested in the throat of the patient. To add to what Group 1 has presented, the complications involved in gonnorhea include infertility, as well as extra-genital involvement -- arthritis. It will not be strange, therefore, if someone with a history of gonorrhea also has gonoccocal arthritis. Diagnosis is carried out through gram staining. It is important to remember, though, that a culture is more sensitive than gram staining in females. This is because it is easier to observe diplococci in males than in females.

Why should we still give Tetracycline? Gonorrhea is usually treated as a mixed infection. Often, when a patient has gonorrhea, he/she will also have chlamydia. It is standard operational procedure to treat all patients who have been diagnosed with gonorrhea for chlamydia as well.

For non-gonococcal urethritis and cervicitis, there are several causative agents. The most common of these is Chlamydia trachomatis. This is the type that we will be discussing. The incubation of this infection takes one to two weeks. The complications are identical to that of gonorrhea. The lab analysis involves gram staining. We look at the number of pus 
cells and, for sex workers, we look for more than 20 pus cells. For those who are not sex workers, more than 10 pus cells signify having tested positive, while 5 pus cells manifest a positive result in males.

We did a prevalence study in Cebu on Chlamydia, using Chlamydiazyme and gram staining. We found out that there were people who tested positive on Chlamydiazyme while their pus cells were zero. This indicates that gram staining is still not perfectly accurate, but since it is the only lab method now available, we have no other choice but to use it.

I have here a chart comparing the discharge characteristics exhibited in the different infections. The odor of the discharge produced by candidiasis varies. In vaginosis, it is fishy. For trichomoniasis, it is foul. Gonorrhea and chlamydia however, cannot be identified simply on the basis of smell. Candida produces discharge of varying amounts, but it is easily identifiable by its white, curdy appearance. Vaginosis produces a large amount of a graywhite discharge. Trichomoniasis produces a yellow-green discharge. For gonorrhea and chlamydia, the discharge produced is white or yellow and looks like pus. The consistency of the discharge produced by candida is thick and clumpy, whereas that produced by trichomoniasis is frothy. In terms of the degree of itchiness, candida and trichomoniasis are characterized by severe itchiness, while it is not as pronounced in cases of vaginosis. It is unusual for gonorrhea and chlamydia patients to complain of itchiness.

While this chart summarizes the basic characteristics of the different RTIs, you must keep in mind that you cannot make a diagnosis on the basis of the discharges alone. Most of the time there is a mixed infection, so the physical symptoms alone can be confusing. So let me show you a few slides so that you will get a better grasp of the differences among the infections. (At this point the speaker showed the group some colored slides of different RTIs.) 


\section{Group 3: Syphilis}

\section{Lab Techniques: VDRL}

Complications: congenital and neurological complications

Prevention: safe sex (use of condoms), maintaining a monogamous relationship

Treatment: penicillin, erythromycin, tetracycline

FP Considerations: condom use, non-insertion of IUD for clients who are suspected to have syphilitic infections

\section{Group 4: Herpes}

\section{Causative Agent: SV Type 1\&2}

Mode of Transmission: sexual contact and close body contact

Common signs and symptoms: pain, vesicular lesions

Complications: high risk of infections of the fetus during delivery, cervical cancer

Prevention: abstain from sexual contact during treatment, yearly pap smear

Treatment: Acyclovir 200mg, $5 \mathrm{x}$ a day for 7 days

FP considerations: condom use

\section{(Dr. Abellanosa resumes her lecture.)}

For the treatment of herpes genitalis, we have a new drug: Valtrex, $500 \mathrm{mg}$. For first infections, this should be taken for 10 days. For recurring infections, 5 days will do. This is also less expensive than Acyclovir. I would also like to remind the group that we need to educate patients with herpes that the treatment will not really kill the virus, but will minimize the symptoms. We need to emphasize that the herpes will recur; otherwise, the patients will complain that the medicine is very expensive and that their symptoms keep recurring. 
As for syphilis, we need to remember that the incubation period is very long and unpredictable. It could be as short as 10 days or as long as 90 days. It is divided into two stages: early syphilis and late syphilis. You cannot really distinguish between the two on the basis of a physical examination alone, however. You can only be able to differentiate the two with a blood test. In patients with primary syphilis, you will observe the presence of a chancre. This ulcer is painless and is usually solitary. There are cases, however, when two chancres appear, usually on the site where the bacteria entered. In females who practice vaginal intercourse, you will observe the ulcer on the labia or on the cervix. If oral intercourse is practiced, the ulcer will be located on the tongue or on the lips, while in cases of anal intercourse, you will see it on the anus. This can also cause enlarged lymph nodes, but this is usually not very painful. Because of this, patients don't usually come for consultation. Eventually, this will progress to secondary syphilis which is manifested by generalized, non-itchy rashes. This, too is often ignored as it is often confused with skin allergies. There can also be the emergence of wart-like structures and patchy hair loss. Secondary lesions also spontaneously disappear, even without treatment. Because of this, the cases that come to us are most often tertiary syphilis which is already severe.

During the latent stage, there are no obvious signs or symptoms, but the patient is still capable of infecting others. You can only detect syphilis at this stage through a blood test. This stage can last up to 30 years. In fact, some people die even before they have discovered that they have the disease. This stage can eventually progress to tertiary syphilis, wherein the lesions involve the heart, the blood vessels, as well as the central nervous system. During the primary and secondary stages, the diagnosis is carried out through dark-field microscopy. For the latent or tertiary stage, serology is used.

As for the treatment during the early stage, you can give a single dose of Penicillin 2-4 million units, but you must do a skin test. If you are not sure that the patient is in the early stage, you can give one injection per week for three weeks. If the patient has any allergies to penicillin, you can give doxycycline or erythromycin for five days. 
Common genital ulcers can easily be distinguished. In syphilis, it is a single, painless ulcer, while herpes results in several painful ulcers. The herpes simplex virus type 2 is the etiologic agent. Things have now changed, though, because of the increasing incidence of oral sex. Previously, type 2 could only be found in the genitalia, while type 1 was found only in the mouth. Nowadays you will find type 2 in the mouth and type 1 in the genitalia as a result of the practice of oral sex.

Herpes usually starts with either single or multiple vesicles which are blister-like and filled with water. They look like chicken pox blisters, only they are closer together. These initial vesicles then rupture, causing the growth of shallow, painful ulcers. These usually last 2-4 weeks before disappearing. These recur, however, about 50 percent of the time.

Complications include cervical cancer, especially if the papilloma virus is also present. There are also risks of fetal or neonatal infection. Diagnosis is based on the clinical manifestations of the disease. This is not difficult, since herpes is very distinctive. Treatment is carried out with $200 \mathrm{mg}$ of Acyclovir, five times daily for seven days, or else with this new drug Valtrex, which is less expensive and can be taken twice a day. Again, it is very important to stress that herpes recurs most of the time. As for family planning considerations, if ulcers are present, you should not use an IUD. If an IUD has already been inserted, it is better to remove it.

The health education issues to be emphasized for these types of infections should include the "four C's": compliance, counseling, contact tracing, and condom use. Compliance refers to the ability of the patient to follow the instructions on taking the medications, such as the amount of drugs, the interval of intake, and the full number of days to complete the treatment. The principle of contact tracing is based on the fact that it not enough to treat just the client. All of the client's current sexual partners must also be treated.

Let me show you some slides of syphilis and herpes cases. 
(At this point, Dr. Abellanosa shows and discusses various slides showing the physical manifestations of syphilis and herpes.)

As a final reminder, I would like to emphasize to the group that it is essential to wear gloves all the time, not just when you are examining lesions, ulcers, or discharges. The slides showed hands without gloves, but those were the patient's own hands. A medical technologist once told me to warn her ahead of time if the patient that she would be handling had AIDS, so that she could wear gloves. I told her instead that I did not have to tell her, as she should treat every specimen as contaminated. 


\title{
GENITAL SKIN CONDITIONS AND HIV/AIDS
}

\author{
Dr. Erickson San Juan
}

Good afternoon once again. My topic this afternoon deals with other STDs whose clinical features are manifested on the skin.

The first of these are genital warts or condyloma accumulata. These are caused by a virus called the human papilloma virus or HPV. This is a slow-growing virus with an average incubation period of four months. Clinical features of genital warts are mainly single or multiple soft, painless, and cauliflower-like growths. Occasionally, the newer lesions look like a polyp; however, if you examine them under a magnifying glass, you will still see spiny projections on the surface. Genital warts are transmitted through sexual contact with an infected person. Complications include obstruction of the vulvo-vaginal area because the warts have a tendency to grow as big as a vegetable. In some cases, pregnant women have to undergo caesarian section because their vaginal warts have grown so big that they block the vaginal canal. A second possible complication is penile and cervical carcinoma. I would recommend, therefore, that if a patient is diagnosed with genital warts, a cervical pap smear should be done. Treatment of genital warts includes podophyllin 10 or $25 \%$ in a compound tincture of benzoin. This should be applied on the wart only, and not on normal tissues as this medication is very strong. It is also possible to use Duofilm (salicylic acid). After the application of these medicines, you should retain the speculum inside the vagina until the wart dries. Another mode of treatment is electrocautery. Some doctors use cryo-therapy which makes use of dry ice shaped as an instrument which is placed inside the vagina.

The next STD is pediculosis pubis, sometimes called pubic or crab louse. The clinical features of this are itchiness and rashes in the pubic area. You will observe elevated red spots near the hair shaft. Sometimes you will even see the eggs of the lice. These lice can also be found in the axillary and chest hair, although you will not find them in head hair. They can be transmitted through both sexual and non-sexual contact. You can get infected through the 
use of contaminated beddings or clothing. Having poor hygiene and multiple sex partners also increases the risk of infection. Treatment is carried out with an application of Lindane or Gamma-benzene hexachloride $1 \%$ lotion onto the affected areas at bedtime. This should stay for about eight hours before being washed off, at which point a new application should be placed. This lotion is not recommended for pregnant women or children below the age of four, as it is neurotoxic.

The next STD we will take up is molluscum contangiosum which is caused by the molluscum contangiosum virus. This is not very common here in the Philippines. The incubation period is from a week to six months. The clinical features are small, pinkish umbilicated papules on the genital area which are treated by pricking them with a needle and applying phenol. I have yet to see a case of this, so I will not say much about this type of infection.

Scabies is caused by the sarcoptes scabie. The incubation period for new patients is two to six weeks and one to four days for recurrent cases. What are some of the clinical features of this skin condition? First is intense nocturnal itching, often to the point that the patient is not able to sleep. Scabies is actually the number one dermatological problem here in the Philippines. It is transmitted through skin-to-skin contact, in both sexual and nonsexual cases. Scabies is contagious until the mites and the eggs are destroyed. The treatment is carried out by applying Lindane $1 \%$ lotion or cream on the skin from the neck down. Scabies is predominant in the interdigital areas, on the hands, the feet, the buttocks, the wrists, under the breasts, and on the pubic area. The patient should be advised to shower at bedtime, apply the cream, and wash in the morning. Everyone in the family should undergo this treatment because scabies can also be contracted through the use of infected beddings, linen, clothing, and mats. All beddings and linen that might be affected should be washed thoroughly, dried well in the sun, and then ironed to ensure that the scabies are killed. For children under ten years of age as well as for pregnant and lactating women, Benzyl-benzoate $25 \%$ is recommended. 
In general, there are not many FP considerations for RTIs which cause genital skin conditions. They do not really affect an individual's choice or use of an FP method. Even women with vaginal warts involving the cervix can still continue to use oral contraceptives and IUDs, except of course in cases when the cervix has already become obstructed. Still, when being treated for scabies as well as other RTIs, patients should be advised to use condoms and spermicide, especially if they have multiple sex partners. They should also be instructed to refrain from sexual activity if their partners are being treated for an RTI. We must also emphasize to the patients that it is essential that they comply with and complete a whole course of treatment. This is a big problem in the social hygiene clinics. When we give a one-week prescription to our patients for non-gonococcal urethritis or gonorrhea, what really happens is that the patients will take the medicine for only two or three days. As a result, the infection usually recurs. At present, however, there are medications which can be taken in a single dose. These seem more expensive, but if you compute the total cost, these will actually come out cheaper. Lastly, it is also important to recognize the need for a followup if the patient's condition does not improve or if it worsens.

Let us proceed to HIV infection and AIDS. We all know that HIV and AIDS are caused by a virus called the Human Immunodeficiency Virus. There are two types of HIV: type 1 and type 2. Type 2 was recently found in Cameroon, Africa. Aside from this, type 1 alone has several varieties, such as sub-types A, E, and O. It is the different variations of the HIV virus that make it difficult for our researchers and health experts to come up with a vaccine.

So what is the difference between being HIV-infected and having AIDS? The moment the HIV virus has successfully entered the system, the patient is already HIV-infected. At this moment, the patient is immediately infectious, even while asymptomatic. Once in the bloodstream, the virus will attack the immune system, particularly the T4 helper cells. These cells are responsible for informing the other lymphocytes to counter-attack with antibodies. Normally, our T-cell count is around 1000, but, because the virus is continually destroying 
T-cells and replicating inside the T4 helper cells, the T-cell count in HIV infected patients usually decreases to a level of less than 200. It is at this point that the patient is diagnosed as having AIDS, whether symptomatic or asymptomatic. In most cases, however, once a patient's T-cell count has become less than 200, the disease will almost certainly have manifested itself already. At this level, the body becomes very prone to opportunistic infections. The most common of these here in the Philippines is tuberculosis, so most of our AIDS patients die of tuberculosis. Once a patient has developed full-blown AIDS, he/she has an average of two to three years to live. The time that it takes, however, for the T-cell count to decrease from 1000 to 200 is about eight years.

What are the modes of transmission of HIV? One is having unprotected sexual intercourse or sex without using condom. Second is blood-to-blood transmission, such as receiving infected blood during a blood transfusion or sharing of infected needles among drug users. Third is vertical transmission, which is infection transmission from the mother to her child. This does not have to happen in the womb, as HIV can also be transmitted through breastfeeding. The body fluids that can contain a sufficient amount of HIV to infect other people are semen, blood, vaginal secretions and breast milk. Actually, HIV is also present in tears, urine, and saliva, but the amount is not enough to cause an infection. For instance, it would take about 32 liters of saliva to transmit the virus.

The first HIV lab procedure is the particle-agglutination test. This is actually a screening test and is not yet confirmatory. If you test positive in this test twice, the specimen is then sent to an RITM or BRL for confirmation. What we use here is the Western blot. The reason a person should undergo an HIV antibody test every six months is because it takes around six months for the body to develop a sufficient amount of HIV antibodies for the test to be able to detect.

There are two types of HIV drugs: the nucleoside analogs and protease inhibitors. Included among the nucleoside analogs is AZT which is given in a dosage of $200 \mathrm{mg}$ three 
times a day. The cost of AZT alone is about P 7,244 per month. Doctors give one nucleoside analog and two protease inhibitors. This could raise the cost to about P 30,000 per month. There seems to be some good news, however. Recently, Time magazine did a story about their choice for man of the year, Dr. Ho. He found that if a patient is diagnosed to have been infected with HIV and is able to receive HIV drugs (AZT and protease inhibitors) early, the virus disappears. Catching the virus early, while it is still contained in the blood stream, makes it easily reached by the drug. If the patient waits too long, the virus enters places where the drug cannot penetrate, such as the meninges of the brain. Now Dr. Ho is looking for a drug that can penetrate these "unreachable" places.

With regard to maternal transmission, there was a study which involved mothers who had been found to be HIV-positive during a prenatal exam. In the first trimester of their pregnancy, these mothers were already injected with AZT. During the time of delivery, they were again injected with AZT. Through this process, the doctors were able to reduce the transmission of HIV by $70 \%$. In addition to this, AZT was also found to have no adverse side effects on the fetus.

At this point, I would like to show you some slides of the different skin infections which we discussed earlier in order to give you a better idea of what they look like.

(Dr. San Juan then showed the group slides of different genital skin infections.) 


\title{
PELVIC INFLAMMATORY DISEASE AND INTRODUCTION TO LABORATORY METHODS IN RTI CASE MANAGEMENT
}

\author{
Dr. Jesus C. Encena
}

The most common presentation of Pelvic Inflammatory Disease or PID is lower abdominal pain. This is a result of an infection of the lower genitalia which eventually rises up to involve the reproductive organs above the cervix. When the cervix and the organs below it are infected, the infection is called a lower genital tract infection. When the uterus and its endometrial lining, the fallopian tubes, and the ovaries are also infected, this is called an upper reproductive tract infection, more commonly known as Pelvic Inflammatory Disease. Sometimes only the uterus is infected; at other times, the fallopian tubes are involved. It is not necessary that all the upper reproductive tract organs be infected for it to be called PID. Even if only the uterus is infected, it is still considered a PID.

What are the most common organisms that cause this? First, we have gonorrhea, chlamydia, and anaerobic bacteria, which cause bacterial vaginosis. In mild or moderate PIDs, the causative agent is usually gonorrhea or chlamydia. Anaerobic bacteria are usually at the root of severe PIDs. Severe PIDs can result into serious complications and can even lead to death, so it is very important to understand this type of infection.

PIDs can cause major damage to the pelvic organs and can result in infertility, recurrent infections and abscesses, ectopic pregnancy, chronic pain, sepsis, and death. Once PID develops, every effort must be made to treat the condition adequately. Before the treatment can be initiated, however, we should make sure that the diagnosis is correct. How is this done? History taking will elicit symptomatic data on this. The woman may experience mild to severe abdominal pain which is usually bilateral, concentrated above the lower abdomen ("puson"), fever, and chills. In addition to this, vaginal discharge is also reported, as well as pain during intercourse. We should, however, keep in mind that PID is not the only 
consideration for lower abdominal pain. If you ask about the patient's menstrual cycle, you may find out that it is only dysmenorrhea. If the patient is in the middle of her menstrual cycle, the pain might be caused by the rupture of the egg from the ovary. If lower abdominal pain is coupled with symptoms of pregnancy plus vaginal bleeding, this gives a presumptive diagnosis of an ectopic pregnancy. This is a very dangerous situation, so it is important to take the history of the patient completely and carefully.

One sign of PID is abdominal tenderness, with or without rebound. When can you say that the abdomen is tender? When you palpate the abdomen, and the patient says it is painful, then you can say that there is abdominal tenderness. If there is rebound tenderness, this means that there is an inflammation inside. The things that irritate the abdomen often require surgical intervention.

How do you say it is a positive cervical motion tenderness? During the bi-manual exam, when you manipulate a part of the cervix, and the patient complains of pain, then you can say that there is motion tenderness. Bi- manual exams and speculum exams can actually save lives. When you insert the tip of your finger into the cervix during the bi-manual exam and the patient complains of pain, this is a positive cervical motion tenderness. Moreover, you should watch out for ectopic pregnancy. There is also positive cervical motion tenderness in pregnancy.

It is also important to know when to refer a client. Most PID patients need hospitalization because PID can be fatal. You should refer women to the hospital if the abdominal pain has guarding or rebound tenderness. Abdominal guarding is when there is rigidity upon palpation. If you find that the abdomen is hard, this is "guarding". The abdomen should not be rigid or painful; it should be soft. Watch out for those types of patients and refer them to the hospital for possible surgery. You can also refer women complaining of abdominal pain for possible ectopic pregnancy if their menstruation is overdue. 
What should you do in situations where there has been a recent pregnancy or an abortion? Why should you refer a woman who has just given birth and is experiencing abdominal pain? There is a possibility that there was an incomplete delivery of the placenta and a PID has occurred. The same thing may happen with recent abortions. Aside from bleeding, retained placental tissues are dangerous, since they can be a source of infections.

There is also the matter of pelvic masses, which can point to abscesses or ovarian cysts. If you find that the abdomen is tender and you feel a lump or mass upon palpation, you need to refer the patient. Please make sure, however, that the lump is not her urinary bladder which may be full.

A fever of 38 degrees Celsius or higher is a sign of the start of sepsis and infection. In this case, the patient needs IV antibiotics, as well as IV fluids because of possible dehydration.

Women being treated for acute PID should be referred if they do not improve within two to three days from the start of treatment. How do you treat out-patients with PID? First, you should prescribe Cefixime $200 \mathrm{mg}$. plus Doxycyline for the chlamydia, one capsule for two weeks. Metronidazole is prescribed for the anaerobic bacteria, twice a day for two weeks. I would like to point out, however, that Doxycycline, Metronidazole, and Tetracycline cannot be prescribed for pregnant women.

Let us discuss the FP considerations. IUDs should not be used in women with a recent history of PID. The demarcation for "recent" is within three to six months. Women with trichomoniasis are at risk of having other RTIs, so IUDs should not be advised for them. In addition to this, women who have had PIDs are at an increased risk of ectopic pregnancy and should use more effective forms of contraception such as oral contraceptives. Oral contraceptives are associated with a lower incidence of PID. No family planning method can 
totally eliminate the risk of developing PIDs. However, condoms may provide a certain degree of protection, if used properly.

In terms of health education, we need to inform the patient that all her partners need to be treated in order to avoid the "ping-pong phenomenon". While a PID patient is being treated, sex should be temporarily prohibited. Those with a PID who experience delay in menses should have a check-up.

If there are no questions, let me just give a brief introduction to the lab techniques that will be used in this study. For candida, we do either wet mount or KOH. For trichomoniasis, the same procedures are used. For bacterial vaginosis, we use wet mount and the Whiff's test where one drop of vaginal discharge is placed on the slide along with one drop of $\mathrm{KOH}$. If there is a fishy odor, the test is positive. For gonorrhea, we use the gram stain for which the confirmatory test is culture sensitivity. For syphilis, we have RPR or VDRL and the confirmatory test is TPHA. For the purpose of this study, we will upgrade the laboratories in your area and we will provide for the gram stain set, the $\mathrm{KOH}$, slides and a couple of other things. We will also invite your medtechs to a three-day refresher course at the Northern Mindanao Medical Center.

Along with the instructions I gave for the $\mathrm{KOH}$ test, I would like to add that if the client has profuse vaginal discharge, it is better to perform a speculum exam. Look for cervical discharge, get a cotton swab, get a drop and mix it until it is fine and homogenous. Add a drop of $\mathrm{KOH}$, mix, and then you can do the Whiff's Test. The medtech will then do the interpretation and staining.

I think that's about it for our discussion of PIDs. Thank you very much. 


\title{
INTRODUCTION TO THE SYNDROMIC MANAGEMENT OF RTIS
}

\author{
Dr. Ilya Abellanosa
}

By asking for the history of the patient, and taking into account the signs and symptoms, the provider can give some form of management. There are two types of management: syndromic management and basic laboratory management.

Why do we need to study syndromic management even if we have laboratories and medtechs? Syndromic management of RTIs was introduced for a number of reasons. First of all, there are serious health consequences of untreated RTIs, such as PID, infertility, etc. There are also social consequences, economic concerns, the cost of screening and all the expensive diagnostic and laboratory techniques. Even a simple gram staining for instance, can cost 50 pesos. More important, there are studies that show that the presence of STDs will increase one's risk of getting HIV. A study showed that just by treating STDs, the prevalence of HIV would be reduced. I think, therefore, that it is important that we treat our patients for STDs right away in order to prevent the spread of infection. Women with chlamydial infection have a disproportionate increase in CD4 lymphocytes. In addition to this, by treating STDs, we reduce chances for men to acquire HIV. With AIDS around, gonorrhea, syphilis, and herpes are fair warning.

The syndromic approach relies on clinical syndromes like genital discharges, genital ulcers, abdominal pain , and scrotal swelling. On the other hand, the etiologic approach is based on lab results. For example, if the test is positive for gram negative diplococci, then you treat the patient for gonorrhea.

You might ask, if we have a lab, why do we need to practice syndromic management? Most of the time, we cannot get the lab results immediately. In contrast, just by using the syndromic management, you can give immediate treatment to the patient. More 
than 20 pathogens can be transferred from person to person through sex. It is possible, therefore, that while you are looking for the right lab procedures for the patient and waiting for the results, the patient can be infecting other people. Even a confirmatory culture takes two days before the result can be known.

Second, we also have a limited range of lab facilities and techniques. This is the main reason for using syndromic management.

There are several advantages of syndromic management. First, it is simple and inexpensive. Second, it requires minimal training. And, third, the health worker can provide immediate treatment. There are also some disadvantages, however. As was mentioned, 80 percent of gonorrhea cases in women are asymptomatic, so if you use syndromic management you cannot treat these asymptomatic patients. As for the treatment, you will have to treat a whole array of diseases. If a patient turns up with vaginal discharges you have to treat for gonorrhea, chlamydia, moniliasis, bacterial vaginosis, as well as trichomoniasis. It is also important to have the necessary drugs in our clinic because if we only rely on the patients to buy the drugs themselves, we cannot be sure that they will obtain the medicines they need.

Syndromic management is not limited to diagnosis and treatment; it includes follow-up and contact tracing, as well as giving health education.

Here is the first flow chart. The patient comes in with vaginal discharges. You are supposed to take the history. Make sure that you know how to take accurate and thorough histories. The most important part of the history is when you do the risk assessment. What are the factors that increase the risk of getting an infection? Poor hygiene, multiple sex partners, past infections, the type of occupation (specifically, whether a sex worker or not), whether the partner is also experiencing the same symptoms, profession of partner, etc. Do you agree with the finding that long distance drivers, military men, and policemen are at a 
higher risk? When you are away from your family, the temptation to have sex with someone else is probably stronger. You should ask the client if her partner has been away from home during the last two months. Asl also, "Have you had more than one sexual partner in the last three months?" For us providers, how will we ask this question? Do we just ask it directly? Before we start interviewing the patient, trust must first be established. You assure them that all the information they give will be kept confidential. You must stick to the rule of confidentiality. This is very important, especially since we are talking about RTIs, many of which are STDs. The information that the patients give is very private. Remember, though, that the main point of asking the patient these questions is to assess his or her risk of getting the infection. If the risk assessment is positive, you should treat for vaginitis and cervicitis. If the risk assessment is negative, you should treat for vaginitis only. Give treatment for trichomoniasis and bacterial vaginosis. The flow chart also lists the medicines that should be prescribed for each particular RTI.

If you have a speculum, you can do the pelvic examination, but you should still do the history taking. With a positive risk assessment, you can treat for vaginitis and cervicitis. If you examine the patient and see discharges in the cervical area, treat for cervicitis and vaginitis. If there are no discharges, treat only for vaginitis.

Tomorrow we will have case studies and role playing. A patient will come to you and give her complaints. You will determine what flow chart to use and what questions to ask. 


\title{
GENDER AWARENESS AND SENSITIVITY
}

\author{
Ms. Aida Santos \\ Consultant, WEDPRO
}

I am from the Women's Education, Development and Productivity Research Organization, which is a women's NGO in Manila. We have an office in Angeles City and we are connected with the Bases Conversion Program. We once did a relevance study which included a comprehensive health program. Right now, we are running an integrated progam in the former Clark Air Base.

My task today is to conduct some sort of a gender sensitivity orientation. I really cannot call it a training, as a real training would take about three or four days. My role today is to simply be a resource facilitator who would help the group form some sort of systematization of knowledge of gender, and in the process, possibly sharpen our understanding of this concept.

Let me begin with an exercise that will introduce us to the definitions of the terms that we will be using today.

(At this point, Ms. Santos asked the group to write on a sheet of paper three attributes of being a man and three attributes of being a woman. They were also asked to give the reasons for listing such attributes. On another sheet of paper, the participants named two things that they liked about themselves and two things that they did not like. The various answers were then summarized and discussed.)

The attributes that you listed for males and females are what we call "attributes of gender". Performing this exercise made you look into yourselves and analyze what it meant to be a person in terms of a two-gendered society. As a health provider, many issues that you deal with in your practice are related to yourselves as women and men. I think this is 
especially true in FP programs. You cannot separate the type of treatment you give from who you are as people. If someone comes up to you and talks to you about his or her problems, the particular way that you relate to that person is a result of the issues that you yourselves face as mothers, wives, fathers, or husbands. I believe that the main reason many of us have difficulty counseling patients is because we have lost touch with what we actually face as women and men outside of our professions--as just human beings. I hope that after today's session we will come to some sort of realization about this.

I asked myself this question last night: why do we need to incorporate RTI management in FP service centers? I was able to come up with four possible answers. First, I realized that by incorporating RTI services into regular FP services, we would be able to connect different illnesses that are related to reproduction. There is a lot of literature that deals with the relation between the type of FP method that is being used with reproductive illnesses. All illnesses that are related to reproduction automatically fall under the category of Reproductive Tract Infections. Thus, there will always be a close relation between the two types of services: family planning and RTI services.

Another reason why this sort of integration is needed is to aid in the de-stigmatization of STDs and RTIs. Usually, STDs and RTIs are identified as "women's illnesses", as if the men are not capable of also contracting them. Integrating RTI services would therefore provide a venue to de-stigmatize STDs. There are so many moral judgements that are attached to these diseases. Once a woman has contracted an STD, many people will automatically assume that she is a commercial sex worker.

Third, this is also a way to bring in the concerns of the males, as well as to increase their participation and responsibility. Reproduction involves two human beings. If we fail to keep this in mind, how will we be able to impart to our clients the importance of both parents getting involved in the reproductive process? Why are men so uninvolved in our FP centers? Maybe because the services that are available to them are very limited. Most men 
do not think that reproduction is included in their area of responsibility. Most of the contraceptives that are available are female- oriented, after all.

Finally, if we will be able to integrate RTI services into the FP program, we will possibly be able to imbue the FP services with a gender perspective and a reproductive health and rights framework. When you talk about family planning, you also talk about reproductive health, and when you talk about reproductive health, you also talk about reproductive rights. These rights are enshrined in our Constitution, as well as in the numerous UN conventions, all of which the Philippine government is a signatory. Being part of the health system, you are also bound and committed to protect and preserve the principles of human rights as well as the ethical issues involved in the health care system.

Let me now continue with some definitions of terms. What is the difference between sex and gender? Sex refers to the biological and physical differences between men and women. Gender is our concept of what femininity or masculinity is. Actually, gender is socially constructed. We don't come out of our mother's womb saying, "I am feminine, therefore I am going to be soft-spoken." Unfortunately (or fortunately) women are the value carriers of the social construction. They are the nurturers, especially in our society. This is connected to the fact that only women can get pregnant and give birth. It seems as though this is taken for granted: it is just assumed that a woman should give birth to and rear a child. The truth of the matter, however, is that reproduction is not necessarily natural. A woman may choose not to have a child. Reproduction is a choice. Reproductive rules for men and women are not and should not be considered natural. They are social constructs. Religion does this. Culture is also involved. Even if you want to change your ways, it is extremely difficult to go against culture and religion.

Most of the issues that we have been discussing today involve issues of power. There is a power aspect to the relationship between the service provider and the client. In Cagayan Valley, for instance, they have the highest rate of ligations and are considered a success 
story. The problem, though, is that many of these ligations were imposed upon the clients. Batangas also has a similar situation. There is definitely a power gap between the client and the one who is giving the FP service. As health service providers, you have the choice whether to empower or disempower your relationship with the client. You can make choices open, or you can control the choices that your client makes. It's up to you.

Ideally, the model that we should follow in providing FP services should be one of providing information to the clients, rather than one of negotiation or control. There is no guarantee, though, that this will actually happen. At the health center level, the people seem so committed to a non-coercive type of health service, but when you observe what is really being practiced at the local levels, there is a lot of coercion. In Davao, for example, the service providers still talk about "motivation", which means that they try to find ways by which they can convince the clients to use family planning. Actually, we should not even be convincing the clients. That is not what counseling is about. It is simply providing the clients with all the necessary and pertinent information, and allowing the couple to make their own personal choice.

At this point, I am going to present some data that the National Commission on the Role of Filipino Women has gathered in order to give you a better idea of the areas of concern that we will be discussing in relation to health.

One interesting piece of information that we can find is the fact that our population is a young one. This would imply, therefore, that most of our services should be geared towards the greatest percentage of our population: the youth.

Our male-female ratio is almost 50/50, but there are more elderly women now. If the $\mathrm{DOH}$ is truly promoting the life-cycle approach, then it should not concentrate its concern with only the reproductive years of women and men. The years before and after are also very important. I keep saying to friends, for instance, that I am going through the first stage of 
pre-menopausal syndrome and I do not know where to go for services. I am sure there are many other women out there who have the same problem.

Let us look at our families and households. The number of females who are household heads is increasing. This would imply many things. For one thing, this may have a great impact upon the woman's health, since she now has so many burdens and responsibilities. Take note that we are talking here of holistic health, which includes mental and emotional health as well as physical health. A lot of Filipino women bring in more money than the men nowadays. We have so many overseas migrant workers, a majority of which are women.

What about domestic violence? Ideally, this should be related to your program. A random survey in Metro Manila showed that 11 out of 12 women are battered. Domestic violence is an essential issue in an FP program, because it is often a reason for discontinuation of services. Many husbands do not like the idea of their wives using artificial contraception, and they beat them up to make them stop.

What is the situation of women in the workplace? In spite of the fact that a majority of our migrant workers are women, there is still a wide gap in male-female employment in our country. The figures show that there is lower labor force involvement for women, and still a prevalent bias for hiring males. In terms of wages, the statistics show that for every peso earned by a man, his female counterpart only earns thirty-five to forty-seven centavos. In addition to this, women work longer hours than men. They work to earn money and they work within the home as well. This is what we call the "double-day". In addition, men generally occupy the highest occupational ranks as well as the highest paying positions. Women are largely given responsibility for housework and the family, thereby impeding their opportunities to use their training and skills for paid work. 
The situation of women's health is not much better. An important part of this issue is abortion. I was there during the presentation of the abortion study of UPPI and the abortion rates were amazingly high, and the unsafe abortion statistics were equally as shocking. The study linked abortion to failure of contraceptives.

Anemia is another problem. Anemia is high among infants and lactating mothers. In 1993, almost half of infants and lactating mothers were anemic. This is really high for a country that is supposedly about to become a "tiger economy". Health, after all, is a major indicator of development.

Contraceptive use has been increasing. However, if we consider that we have had an FP program in our country for a very long time, the acceptance rate is still low. We should ask ourselves as well whether the FP program is addressing one of the most sexually active groups, the teenagers. What is the protocol? Do you accept clients who are 16 years old and unmarried? If they are not accepted, many of them get pregnant and then have unsafe abortions.

Maternal education is a major determinant of post-neonatal deaths. I don't think that maternal education means high education in terms of the academe; rather, it means access to information, knowing what to do as a mother, as a nurturer, and how you can access the services available to you. The highest rates of post-neonatal infant and child mortality are found among children born to teenage mothers.

I have tried to show you the ways in which gender disparities are institutionalized on a national level, in various fields of our lives, both private and public. In this sense, therefore, gender is a political issue. As health providers, you should try to come up with ways in which you can make your respective fields less gender-oppressive. What I have tried to show you is that what we are really talking about here is domination and subordination. Gender differences are shaped by ideological, historical, economic, and cultural determinants. As such, your own services are bound by these gender issues and concerns. As health providers, 
you have the responsibility to look at gender differences and acknowledge the fact that women and men are in different situations, which will, in turn, determine the terms of their access to your delivery programs.

Women are agitating for change. All of us can do something to help bring this about. Maybe we can start with ourselves, then our children. It is too abstract to simply say that the progress will be accomplished through social change. If we can somehow manage to look into ourselves and personalize the issues, we may succeed in having a truly gender-sensitive program.

I understand that the issue of having separate equipment for prostitutes and for the general population has also come up. There seems to be a fear that the word will spread that the FP centers are going to cater to the prostitutes and that your regular FP clients will no longer visit the clinic. First of all, I cannot see how you can ever really know for sure that a woman is a prostitute. While you may know of some licensed prostitutes, what about the unlicensed ones? They do not come to you and introduce themselves as a prostitute. They can look like your own child. Many of them are very young. Others are mothers and wives by day and only become prostitutes by night. You can never really tell.

Secondly, I have to state clearly that it is a violation of their human rights if you do not provide them with universal access to health services. Health is an essential human right and it should be available to everyone without discrimination. The first principle is equity and equality. Health services cannot be made available to only a specific part of the population. Second is, universal access to FP services, which means it must be across all social classes and cultures. If you segregate your clients, you are not only violating their human rights, you are also contributing to the perpetuation of pre-existing discrimination and prejudice.

Here are four other ethical principles to keep in mind:

- $\quad$ Respect and protect a person's autonomy- You cannot make decisions for the clients. They have to make their own free decisions. 
- $\quad$ Non-maleficence-You maximize the benefits and minimize the harm.

- $\quad$ Justice and equal treatment - The processes involved should be fair and equal.

- Interactive client-service provider relationship- The client is not merely a receiver of information and services, but is also an active participant.

In addition to this, doctors must remember that they took the Hippocratic oath . How can they deny aid from the most vulnerable women, the prostitutes? To deny them this would be to increase their chances of dying. If you really want to stay in the health profession, you should tell yourselves that health workers should not discriminate. When I went to an international conference on AIDS in Vancouver, I realized that most of my seatmates were HIV-positive. This is also how it is in reality. You cannot choose who you want to sit next to. In the same way, service providers cannot choose which clients they will treat. Human rights are indivisible and universal. You cannot say that because a certain woman is a prostitute, then she has fewer rights. If you marginalize certain clients, you are contributing to human rights violations.

In order to sum up the issues that we have been discussing, let me share with you some important points. First, contraceptive assistance is only one component of the reproductive health approach, encompassing maternal and child care, as well as prevention of cancer and STDs. In addition to this, the promotion of gender equality and women's empowerment should replace the conventional approach to women's status. Even with their education, women can still be disempowered, violence can still be done to them. The third point is that women's rights and principles, respect for bodily integrity, and security as persons are key elements in a gender-sensitive reproductive health and rights framework. We are looking at FP services and RTI services as issues that we will probably have to dealt with in the context of sustainable development, as in the empowerment of both men and women.

I believe that this ends our long discussion. I hope that you will continue to discuss the points I brought up in your other sessions. Thank you. 


\title{
INTEGRATED RTI/FP COUNSELING
}

\author{
Ms. Rhea Ravanera
}

DKT International

Let's start by discovering your concepts of counseling and how you apply them daily in the clinic. What we would like to do is to form three subgroups for presentations. Your presentations should last from three to five minutes and should portray a common scenario in counselling based on your own experience.

(Several role plays were presented and then discussed individually, with members of the group giving comments on what transpired during each presentation.)

Since we now have a better idea of what really goes on during counseling in the health centers, let us now discuss the general principles involved in counseling. Counseling is the process of enabling someone to overcome a problem, meet a need, make a decision, or accept a situation. Counseling can be used as both a preventive and curative intervention. Counseling does not mean giving advice, but providing information and options. Specifically, we will be talking about client-centered counseling. This means that the client's needs are the ones that are met and not anybody else's. This means that the client is empowered. We should teach the client to make his or her own decisions. We must give the client the chance to make an informed decision. While I was observing the role play, I was happy to see that many of the skills that are important for counseling were already being demonstrated. Let us talk more specifically about these skills.

First, a counselor must be able to establish rapport. You should be able to gain the client's trust and confidence, as well as to make him/her feel at ease. You can do this by projecting an open and nonjudgmental attitude. Secondly, you should make it a habit to ask open-ended questions, which are not answerable with a simple yes or no. This type of 
question allows you to obtain more information and insight from the client. Third, a good counselor must know how to provide factual, accurate, and relevant information. You should be able to explain things in a language that the client understands. You may have to use local terms, even if you find them vulgar or crude. Fourth, you need to learn the skill of paraphrasing. This is basically repeating what the client said in a different way, but the content of the message remains the same. Paraphrasing is also a way to verify whether you understood what the client was trying to say. In addition to this, there is also the skill of summarizing. Before the consultation ends, you should make the client summarize your instructions to him/her to find out if you were understood.

Praise and encouragement are also important. You should commend the client for coming to the center to receive treatment. You have to remember that seeking treatment, especially for an RTI, is not a very easy thing to do, so you have to acknowledge the brave decision that she made. If you make the client feel important, she will feel that she is getting the best service possible.

Another important skill is active listening. You need to convey to the client that you are truly listening to what he/she is saying. This is also a form of empowering the client. So, you need to make small comments, nod in agreement, maintain eye contact, etc. It is not enough to simply listen to the client. You have to show your full attention through your actions.

Sixth is the skill of reflecting. By doing this, you are encouraging the clients to elaborate on the messages they are trying to convey. If you repeat what the client said, she will tend to give further explanations. In addition to this, you are also ensuring that the two of you understand each other more fully. When you mirror feelings, you allow the client to confront them and gain insight into the various emotions involved. You may discover that there is more than one feeling being expressed. 
Lastly, there is the skill of clarification probing. Often, a counselor has to resort to probing because the clients are not as open about their situation as they should. You may feel embarrassed about seeming too inquiring, but further probing is often necessary. One way to do successful probing is to guarantee confidentiality. You should also make it clear to the client that you will be non-judgmental regarding whatever information she relays.

I usually use some acronyms to help me recall the skills that are required in counseling. In terms of the non-verbal communication that you should give to clients, remember the acronym SOFTEN. S stands for smile, while $\mathrm{O}$ stands for open posture. This would mean leaning forward, with your hands extended. F stands for face-to-face, and T is for touching. You should use this latter skill with caution, however, as it could be misinterpreted. $\mathrm{E}$ is for eye-contact, and $\mathrm{N}$ is for nodding.

There is also another acronym to remember when we refer to the general framework of a counseling session: GATHER. G stands for greet the clients warmly. By doing so, you are establishing rapport and putting the client at ease so that you will be able to draw out adequate information from him/her. The letter A stands for ask the client. You should try to get a complete history of the client so that you will have a clear picture of his or her life situation. You should ask for a history of STDs, if any, and other pertinent information, both for the client and the partner. T stands for tell the client. Tell about modern FP methods and have screening sessions for STDs and HIV/AIDS. As I said before, all the information that you give should be factual. A good integration point for RTI services into the FP program is the promotion of condom use. You can point out that the condom is not only effective for family planning, but also serves as protection from STDs, including AIDS. You must keep in mind, however, that you should not let your biases for a certain method interfere with the information you provide. When you present the different methods, you need to present both their advantages and disadvantages. The information that you provide the clients should be complete.

The letter $\mathrm{H}$ stands for help the client make a decision. Once you have provided the client with complete information, you should assist her in making a choice. The choices 
involved are not only those relating to the selection of a particular FP method. You should also facilitate decisions that involve changing a certain risky behavior or seeking treatment for an RTI. One word of caution, however. Do not always expect that once you have provided all the information, the client will follow one of the possible options. You are dealing with human behavior, and humans do not always make rational decisions and often do not choose the best course of action.

After a choice has been made, remember the letter $E$ which stands for explaining the method. It is not enough to present the method to your clients; you also have to make sure that they know how to use that particular method properly. If they do not understand how to use the method, they will probably not use it properly and all your efforts will have been for nothing.

Lastly, the letter $\mathrm{R}$ stands for return visit schedule or referral. In the case of a return visit, you should always emphasize the importance of follow-up. You need to make sure that the infection has been treated adequately. In cases which you feel unable to handle, however, you will have to give the client a referral.

Let me mention some common counseling errors. One is controlling rather than encouraging the client's expression of feelings and needs. Sometimes, without being aware of it, we control the flow of the client's feelings. We emphasize what we would want or expect to see, rather than what the client is truly feeling, so then the counseling is no longer client-centered. You must always accept the client's feelings, whether you agree with them or not.

Another error is making judgements. Don't make assumptions or place moral judgements about the client. This is not part of your job. Helping clients make informed choices is. Don't focus on the attitude of the person, or on the morality of their actions, but on the factual information that they need to know. If they are engaging in risky behavior, don't scold them; rather, just inform them of the dangers of continuing their actions. 
Labeling is another common error. Do not assume that all commercial sex workers have RTIs or STDs. In the same way, do not assume that if a woman is a housewife she cannot have extramarital affairs. Let us get rid of unfounded biases and prejudices. In addition to this, you will also be making a mistake if you engage in over-reassurance. If you try to induce undue optimism by making light of the client's problem, you are hurting the client rather than helping her. If the client has a serious disease, inform her of it. Tell her the truth. In connection to this, you must also make sure that you have supplied all the necessary and relevant information before you help the client make a decision. The risk assessment must have been conducted thoroughly before you try to do any helping.

Interrogating the client is also a common mistake. You must realize that there is a difference between probing and interrogating. Both will supply you with additional information; however, interrogating a client can destroy rapport. When a counselor asks too many pointed questions, the client will often interpret these as being accusatory and judgmental.

It is also a mistake to encourage dependence on the part of clients. The whole purpose of a client-centered approach is to help the clients develop the ability to make their own decisions. Thus, if you spend your sessions undermining the client's independence and increasing her need for your continuing presence, you are contradicting the principles of the client-centered approach. If you keep making decisions for clients, you are teaching them to be dependent on you, instead of empowering them. Secondly, if something goes wrong, it is possible that you will be the one blamed, as the client's choice was made upon your advice.

Now that we have discussed all the issues involved in counseling, let's have another session of role play, this time incorporating the skills and principles we have learned so far.

(Different situations were assigned to three groups and these were presented. After the presentations, the group again discussed what happened during the role plays.) 


\title{
IEC AND COMMUNITY AWARENESS CAMPAIGNS
}

\author{
Ms. Sol Atayan
}

DKT International

This afternoon, I would like to say something about community awareness. Let's start with a definition of terms. What do I mean when I use the term "community"? I am talking about a specific group of people. The grouping is often done geographically, such as "the community of Cagayan de Oro," but there are also several other communities living in that place. For instance, there can be the Muslim community of Cagayan de Oro, or the gay community of Cagayan de Oro. All these groups can be considered specific communities.

I would like to ask the group now about their ideas of educational activities aside from counseling. I would like you to identify the different IEC activities that you are doing right now. Some of you are doing pre-clinic lectures, which are carried out while the clients are waiting for their consultation. Other activities include household classes and community outreach activities. You go to the areas where your clients live and give them FP education. You can also get involved in marriage counseling and post-clinic lectures. You should also supplement these activities with the distribution of IEC materials such as posters, comics, brochures, leaflets, etc. It is important, however, to think about the type of IEC materials we are distributing, whether these are appropriate for our clients. In connection with this topic, I would like to have the group participate in an activity. I will divide you all into three subgroups, with each getting various IEC materials. Your task will be to examine these and identify the criteria for developing good IEC materials. What are the factors that make up effective IEC materials? What are the points that must be considered in developing IEC materials?

(After some minutes of discussion within the small groups, each group presented the criteria that they had come up with.) 
What are the common points that the groups brought up? Summing them up, these are the various factors to be considered in evaluating IEC materials:

Is it culturally sensitive and acceptable? Will the illustrations and words offend the people in the community?

- Is the material directed to a specific group of people, such as an age, sex, ethnic, social, or work group?

- Is the material clear and easy to understand? Will the clients understand the message that the material is trying to convey? Is the language that is used appropriate for your clients?

Are the text and the illustrations clear? Are the illustrations appropriate for the text?

- Is the information that is provided accurate? Does it have a factual basis? Is it technically correct?

It is important for you to be aware of these criteria, because information campaigns also include the development and distribution of IEC materials. In addition, you also have to encourage some sort of positive behavioral change among clients as part of your educational campaigns. Education not only involves lecturing and information-giving, but also helping the clients find solutions to their problems. This is distinct from counseling because counseling involves having a one-on-one dialogue and giving emotional and psychological support to the client. Education campaigns are geared towards addressing the particular needs of a group, rather than of individuals.

What are the characteristics of a good educator? Let me enumerate them. A good educator:

- speaks loudly and clearly

- presents the materials at a balanced pace, not too slowly, yet not too quickly

- presents accurate information that is of use to the client 
- shows confidence

- makes good use of educational materials

- listens to the clients and responds appropriately to feedback

$\checkmark \quad$ is able to hold the group's attention

- makes the clients feel at ease in a comfortable environment

In addition to this, there are also certain concerns in conducting educational activities that we should take note of:

- differences in perceptions of your participants - The participants may not have common experiences, so their perspectives will vary.

- differences in language, both verbal and nonverbal - Some of your participants may not speak the same dialect. Or they may use different ways of getting their message across.

- differences in social customs - Different cultural groups have different social mores, so it is useful to be familiar with their particular beliefs and taboos.

- differences in social status or economic situation - If your group is heterogenous, you cannot avoid differences in perspectives, especially among people from different social classes.

- competing messages - Perhaps as a result of the sheer volume and variety of the messages that we are giving to our clients, some of the participants get confused.

- people who are resistant to change - Many Filipinos are conservative and are quite resistant to new developments and modern ideas.

- lack of respect - This would refer not only to the way in which the clients regard the service providers, but also to the way the providers treat the clients. Respect should therefore be a two-way process.

How are we supposed to overcome these obstacles? These are the suggested strategies based on the AIDS-LAP manual: 
- Messages should be simple and concise.

- Use appropriate visual aids to support the messages you are trying to impart.

- There should be a good environment for message transference - The environment should be conducive to learning. You shouldn't hold your educational sessions just anywhere.

- There should be common knowledge of both the educator and the recipient - You should know your audience in the same way that your audience should be able to know you, so as to create some sort of intimacy.

The lecturer should be able to elicit and respond to questions from the clients.

Let me end this discussion with a few points to ponder. People remember only approximately 20 percent of what they hear and see, while they discover 80 percent for themselves. This is the reason we must become learner-centered. We must be in tune with our audience and be able to sense their needs and help them find ways to address these. 


\title{
CONTEXT OF THE RTI MANAGEMENT INTEGRATION PROJECT: COMPONENTS, EXPECTED OUTCOMES, AND METHODOLOGY
}

\author{
Dr. Marilou Palabrica-Costello
}

Good morning, everyone. I am sorry I wasn't able to join you last night at the socials but I did send representatives from my family. I'm happy that you had a chance to unwind because I know that this has been a hectic schedule for you during the last few days.

One of the things that we have constantly been going back to is the fact that this training on RTI case management is part of a bigger project to test the feasibility of integrating RTI management within the Family Planning-Maternal Health program. This means, of course, that you are going to be our partners in carrying out this important activity.

At this point, I would like to show you a few overheads to further describe this project. To begin with, what were some of the preliminary concerns and the rationale for undertaking this study in the first place? The literature shows that the prevalence of RTIs worldwide is quite high. While we still do not have clear-cut data on this in the Philippines, we do have anecdotal evidence that suggests a similar situation over here. We also noted that many women with RTIs do not seek treatment. What we are seeing, therefore, is only the tip of the iceberg.

There are several factors why women do not seek treatment for RTIs. Statistics show that about 80 percent of women who have RTIs are asymptomatic. In some of these cases, women feel the symptoms but do not regard them as serious enough to warrant their seeking treatment. These women may also not have the time and resources to pay attention to all the symptoms they are experiencing. Another possible reason women do not seek treatment is because of the social stigma that is attached to these illnesses. As you know, these infections are often associated with commercial sex workers and people who have multiple sex partners. 
We noted during the situation analysis that there are no standardized procedures for RTI management now being followed in the LGU health centers. Although syndromic management is occasionally presented as a standardized approach, it is now recognized that there are limitations to this approach. Since this was developed for resource-poor settings, some areas may be too advanced for it. It also calls for the immediate treatment of patients without necessarily having a doctor present. In this case, therefore, a midwife might be the one to write a prescription for the treatment of the infection. This poses practical impediments to the implementation of such a method since some doctors have expressed hesitancy about allowing such a drastic change.

Another constraint to the use of syndromic management is the fact that when the WHO developed the flowchart, they based it on a wide array of experiences of different countries. The questions that they developed may not necessarily be applicable to our situation in the Philippines, or in other countries for that matter. This is why the WHO requires that the risk assessment questions be validated in the country that is planning to use the syndromic approach. We have not yet done this in the Philippines. There are still many things that need to be examined and tested in this approach to RTI management. I hope our experience here today will contribute to the literature on the syndromic approach to RTI management.

What exactly is the research that we are trying to do? The general objective of the study is to assess the feasibility of integrating RTI/STD services within the LGU health centers. How will we attain this objective? Through an intervention program on integrating RTI/STD prevention and services in these health centers, then evaluating the experience after ten months. This program has several components, the first of which is to train service providers in RTI case management. The goal of this training is to enhance the providers' skills in history-taking, counseling, doing a physical exam, etc. 
A second goal is to help strengthen community education and awareness campaigns. The project will assist in strengthening physicians' ability to conduct health education talks and to develop IEC materials which will be used in the delivery of clinic-based services. The third component is to upgrade diagnostic facilities in the clinics. Dr. Encena will discuss the mechanics of this later on. An inventory and upgrading of the laboratory facilities in your clinics will also be carried out in order for you to be able to provide RTI services according to the model or approach that will be used in your centers. Lastly, there is a component involving drug provision. As you might probably know, this is one of the more difficult and complicated components of the study. We are restricted by USAID regulations from using USAID funds in drug provision, so we had to solicit help from the UHNP, the LGUs, and the DOH to assist us in this particular task. We have obtained a commitment from UHNP that they will provide the drugs needed for the duration of this project in the UHNP areas. This was quite helpful except that Jasaan and Tagoloan were not covered by UHNP. Fortunately, the LGU officials of these places have been very supportive. Mayors Paurom and Emano have both assured Population Council that they will set aside funds for drug provision. We have also obtained assurances from the DOH, through the FPS, of their support in soliciting assistance from drug companies to supplement our existing resources.

What could be the possible outcomes of this study? Let me just enumerate them. We hope that:

1. There will be a greater proportion of women who receive RTI services from the clinics where we have implemented the intervention than from a set of comparable clinics with no intervention. For the moment, the experimental areas will be your areas, while the control areas have still to be identified.

2. There will be a greater proportion of women seeking information on the prevention and treatment of RTIs and STDs at the experimental clinics as compared to the control clinics. 
3. There will be a greater proportion of women receiving counseling and information about the prevention and treatment of RTIs/STDs in the experimental clinics than in the control ones.

4. There will be a greater proportion of women referred for diagnosis and treatment for RTIs/STDs in the experimental rather than in the control clinics.

5. The diagnostic facilities for RTIs and STDs will be more comprehensive in the experimental clinics.

6. There will be a greater proportion of women in the experimental clinics who have knowledge about RTI/STD preventive behaviors and risk factors.

Why are we expecting these changes to occur? First, with regard to RTI counseling and referrals, we hope that this training has helped you become better counselors and made you more sensitive to the needs of your clients. Secondly, since there are going to be some activities connected with community awareness and education, we expect that this campaign will:

- increase the number of clients who are seeking information on RTIs

$\checkmark \quad$ impart additional information to clients

$\checkmark \quad$ and increase the practice of preventive behaviors.

Third, there will be improved understanding of client needs as you become more gender-sensitive. Fourth, refresher training and lab upgrading should bring about better diagnosis, increase the number of referrals, and increase the number of cases being diagnosed and managed.

What are some of the data collection procedures that will be used in this study? First, there will be a comparable set of non-intervention areas. A set of criteria will be used to choose areas that are comparable. Secondly, follow-up data collection procedures will be 
instituted in both experimental and control areas. There will be four data methodologies that will be used:

- clinic records - Records of women seeking referrals and information and FP cases that have been diagnosed and managed

- exit interviews - These will gauge client satisfaction and provide quality of care indicators

- laboratory and facilities check-up

- examination of project records - Especially useful for the DOH and the LGUs will be the cost implications, which will guide the future implementation of an RTI service integration within the present FP program.

Now, I would like to present to you a timetable for the project:

\begin{tabular}{|l|l|}
\hline March 1997 & Training of service providers \\
\hline April 1997 & Refresher training; inventory of lab facilities \\
\hline April-June 1997 & Implementation of research intervention at LGU level \\
\hline July 1997 & Second meeting to assess experiences \\
\hline August 1997 & Further laboratory upgrading \\
\hline August-October 1997 & $\begin{array}{l}\text { Laboratory upgrading (monitored by DOH \& LGU } \\
\text { staff) }\end{array}$ \\
\hline November 1997 & $\begin{array}{l}\text { Third meeting for discussion on development and results } \\
\text { of study }\end{array}$ \\
\hline December 1997 & $\begin{array}{l}\text { Submission of final report and national dissemination of } \\
\text { results }\end{array}$ \\
\hline
\end{tabular}




\section{PLANS OF INTEGRATION}

\section{Carmen Health Center, Cagayan de oro City}

\begin{tabular}{|c|c|c|}
\hline$\underline{\text { STRENGTHS }}$ & WEAKNESSES & RECOMMENDATIONS \\
\hline Supportive LGU & $\begin{array}{l}\text { Delayed arrival of some } \\
\text { medicines }\end{array}$ & Regular supply of medicines \\
\hline Adequate supply of medicines & Lack of space; no privacy & Construction of new buildings \\
\hline Trained service providers & $\begin{array}{l}\text { Inadequate supply of certain } \\
\text { instruments }\end{array}$ & $\begin{array}{l}\text { Request for additional } \\
\text { equipment }\end{array}$ \\
\hline Availability of instruments & Med techs are not well-trained & $\begin{array}{l}\text { Orientation/refresher course } \\
\text { for med techs }\end{array}$ \\
\hline \multirow{2}{*}{$\begin{array}{l}\text { Availability of med techs and } \\
\text { lab equipment }\end{array}$} & Lack of reagents & Regular provision of reagents \\
\hline & $\begin{array}{l}\text { Doctor visits only once a } \\
\text { week }\end{array}$ & $\begin{array}{l}\text { Allow midwife to refer clients } \\
\text { to City Health Office } \\
\text { Provision of standing orders } \\
\text { to PHN and RHM }\end{array}$ \\
\hline
\end{tabular}

\begin{tabular}{|l|l|l|l|}
\hline \multicolumn{1}{|c|}{ ACTIVITY } & \multicolumn{1}{|c|}{ TIME FRAME } & \multicolumn{1}{c|}{ IN CHARGE } & RESOURCES \\
\hline $\begin{array}{l}\text { Orientation of barangay } \\
\text { officials on RTI/STD } \\
\text { management }\end{array}$ & $\begin{array}{l}\text { Second week of } \\
\text { April }\end{array}$ & PHN, RHM, MO & \\
\hline $\begin{array}{l}\text { Orientation of BHWs on } \\
\text { RTI/STD management }\end{array}$ & Third week of April & PHN, RHM & Self-reliance \\
\hline $\begin{array}{l}\text { Actual implementation of } \\
\text { RTI/STD management }\end{array}$ & April & PHN, RHM, MO & $\begin{array}{l}\text { PopCouncil, DOH, } \\
\text { LGU }\end{array}$ \\
\hline $\begin{array}{l}\text { Conduct HH class with } \\
\text { emphasis on RTI/STD } \\
\text { management }\end{array}$ & April-June & PHN, RHM, & Self-reliance \\
\hline $\begin{array}{l}\text { Conduct pre-natal } \\
\text { conference with emphasis } \\
\text { on RTI/STD mgt. }\end{array}$ & Every Tuesday & RHM, PHN & \\
\hline $\begin{array}{l}\text { Individual conference } \\
\text { with FP clients on RTI }\end{array}$ & Everyday & PHN, RHM & \\
\hline
\end{tabular}




\section{Macabalan Health Center, Cagayan de Oro City}

\begin{tabular}{|lll|}
\hline \multicolumn{1}{|c|}{ STRENGTHS } & \multicolumn{1}{c|}{ LIMITATIONS } & \multicolumn{1}{c|}{ RECOMMENDATIONS } \\
Committed health personnel & $\begin{array}{c}\text { Facilities: } \\
\text { - speculum } \\
\text { - laboratory }\end{array}$ & $\begin{array}{l}\text { Provision of needed facilities } \\
\text { and equipment }\end{array}$ \\
Supportive LGU & $\begin{array}{l}\text { Personnel: } \\
\text { - doctor comes } \\
\text { on scheduled visits }\end{array}$ & $\begin{array}{l}\text { Doctor should have standing } \\
\text { orders }\end{array}$ \\
& $\begin{array}{l}\text { All RHMs should be trained in } \\
\text { basic compre and RTI } \\
\text { management }\end{array}$ \\
\hline
\end{tabular}

\begin{tabular}{|c|c|c|c|}
\hline$\underline{\text { ACTIVITY }}$ & TIME FRAME & IN-CHARGE & $\underline{\text { RESOURCES }}$ \\
\hline Inform LGU of research & ASAP & MO/PHN & \\
\hline $\begin{array}{l}\text { Orientation of the RHU } \\
\text { staff and BHW }\end{array}$ & first week of April & MO/PHN & \\
\hline $\begin{array}{l}\text { Inform NGO FP clinic } \\
\text { about the research }\end{array}$ & first week of April & MO/PHN & \\
\hline $\begin{array}{l}\text { Community awareness } \\
\text { campaign: } \\
\text { signboard, IEC } \\
\text { materials, HH classes, } \\
\text { etc. }\end{array}$ & April-December & RHU staff & \\
\hline
\end{tabular}




\section{Lapasan Health Center, Cagayan de Oro City}

\begin{tabular}{|lll|}
\hline \multicolumn{1}{|c|}{ STRENGTHS } & \multicolumn{1}{c|}{ LIMITATIONS } & \multicolumn{1}{c|}{ RECOMMENDATIONS } \\
$\begin{array}{l}\text { Availability of manpower and } \\
\text { facilities }\end{array}$ & MO visits HC once a week & $\begin{array}{l}\text { Reschedule visits to at least } \\
\text { twice a week }\end{array}$ \\
$\begin{array}{l}\text { Availability of FP clinic and } \\
\text { equipment }\end{array}$ & No supply of reagents & $\begin{array}{l}\text { Request for resupply from } \\
\text { UHNP }\end{array}$ \\
$\begin{array}{l}\text { Trained personnel } \\
\begin{array}{l}\text { Dedicated and committed health } \\
\text { worker }\end{array}\end{array}$ & $\begin{array}{l}\text { No signboard announcing } \\
\text { services }\end{array}$ & Provide signboard (c/o LGU) \\
Supportive LGU & 4 untrained RHMs & $\begin{array}{l}\text { Finish construction of the new } \\
\text { HC (c/o LGU) }\end{array}$ \\
Private room for counseling & No supply of medicines for RTI & Request for medicines \\
\hline
\end{tabular}

\section{ACTIVITY}

TIME FRAME

IN-CHARGE

RESOURCES

Community awareness:

- orientation of untrained HP and

volunteers

First week of April

MO/PHN

- attend bgy. council meetings

- signboard

- distribution of IEC materials

First Sunday of April

Third week of April

April-December 1997

$\mathrm{MO} / \mathrm{PHN} / \mathrm{R}$
$\mathrm{MO} / \mathrm{PHN}$

PHN/RHM/BHW

April-December 1997

April-December 1997

April-December 1997
PHN/RHM

Med techs

MO/PHN/RHM
LGU funds

IEC materials from

DOH/ PopCouncil

UHNP funds

Forms from PopCouncil

Case finding
of RTI cases 


\section{Cagayan de Oro Health Center}

\begin{tabular}{|lll|}
\hline \multicolumn{1}{|c|}{ STRENGTHS } & \multicolumn{1}{c|}{ LIMITATIONS } & \multicolumn{1}{c|}{ RECOMMENDATIONS } \\
Very supportive LGU & Lack of separate lab for RTIs & \multicolumn{1}{c}{$\begin{array}{c}\text { construct new building } \\
\text { Availability of foreign funding } \\
\text { orient and equip med techs on } \\
\text { RTI mgt. }\end{array}$} \\
$\begin{array}{l}\text { Availability of personnel trained } \\
\text { in syndromic approach }\end{array}$ & $\begin{array}{l}\text { Lack of private examining and } \\
\text { counseling room }\end{array}$ & new building \\
$\begin{array}{l}\text { Laboratory equipment, supplies, } \\
\text { and RTI drugs }\end{array}$ & $\begin{array}{l}\text { Lack of time for counseling and } \\
\text { treatment }\end{array}$ & $\begin{array}{l}\text { limit doctor's activities to only } \\
\text { one program }\end{array}$ \\
$\begin{array}{l}\text { Presence of tertiary medical } \\
\text { centers and consultants }\end{array}$ & $\begin{array}{l}\text { Delayed procurement of RTI } \\
\text { medicines }\end{array}$ & early requisition of medicines \\
$\begin{array}{l}\text { Good interpersonal relationships } \\
\text { with other clinics }\end{array}$ & & \\
& & \\
\hline
\end{tabular}




\section{Jasaan Health Center, Misamis Oriental}

\begin{tabular}{|lll|}
\hline \multicolumn{1}{|c|}{ STRENGTHS } & \multicolumn{1}{c|}{ LIMITATIONS } & $\underline{\text { RECOMMENDATIONS }}$ \\
Availability of trained manpower & $\begin{array}{l}\text { Med tech reports only twice a } \\
\text { week }\end{array}$ & $\begin{array}{l}\text { Training for med techs and } \\
\text { RHMs }\end{array}$ \\
Six untrained RHMs & Request for lab supplies \\
Adequate facilities & Lack of lab supplies for RTI & \\
& $\begin{array}{l}\text { Lack of basic instruments (e.g. } \\
\text { weighing scale, cabinets, etc.) }\end{array}$ & \\
& & Request drugs from DOH/Pop \\
& & Council \\
\hline
\end{tabular}

\begin{tabular}{|c|c|c|c|}
\hline$\underline{\text { ACTIVITY }}$ & TIME FRAME & IN-CHARGE & $\underline{\text { RESOURCES }}$ \\
\hline $\begin{array}{l}\text { Training of remaining } \\
\text { RHMs }\end{array}$ & Second week of April & PopCouncil/DOH & PopCouncil/DOH \\
\hline $\begin{array}{l}\text { Upgrading of lab } \\
\text { facilities }\end{array}$ & April & PopCouncil/DOH & PopCouncil/DOH funds \\
\hline $\begin{array}{l}\text { Client awareness and } \\
\text { information } \\
\text { dissemination: } \\
\text { - IEC materials } \\
\text { - pelvic exam } \\
\text { - AIDS related } \\
\text { activities }\end{array}$ & $\begin{array}{l}\text { After this training } \\
\text { As the patients come } \\
\text { April-May }\end{array}$ & $\begin{array}{l}\text { Trainees } \\
\text { Doctor/RHM/PHN } \\
\text { RHM }\end{array}$ & $\begin{array}{l}\text { PopCouncil } \\
\text { (existing instruments) }\end{array}$ \\
\hline Project meeting & July & All trainees & \\
\hline $\begin{array}{l}\text { Submission of reports } \\
\text { (monthly and annual) }\end{array}$ & $\begin{array}{l}\text { Every month (monthly) } \\
\text { December (annual) }\end{array}$ & RHM/doctor & $\begin{array}{l}\text { PopCouncil (report } \\
\text { forms) }\end{array}$ \\
\hline
\end{tabular}




\section{Tagoloan Health Center, Misamis Oriental}

\begin{tabular}{|lll|}
\hline \multicolumn{1}{|c|}{ STRENGTHS } & \multicolumn{1}{c|}{ LIMITATIONS } & RECOMMENDATIONS \\
$\begin{array}{l}\text { Six midwives trained in basic } \\
\text { compre }\end{array}$ & $\begin{array}{l}\text { Med tech reports on schedule, } \\
\text { some midwives untrained in RTI } \\
\text { mgt. }\end{array}$ & $\begin{array}{l}\text { Request med tech to report at } \\
\text { least twice a week }\end{array}$ \\
Adequate facilities & $\begin{array}{l}\text { Procurement problems: } \\
\text { - LCE preference for local } \\
\text { supplies } \\
\text { - efficacy of drugs }\end{array}$ & Procurement of standard \\
& medicines \\
Permanent physician & Lack of sterilizers & Request sterilizers from LGU \\
Committed health workers & $\begin{array}{l}\text { Religious interference in FP } \\
\text { implementation }\end{array}$ & \\
& Not all personnel trained in RTI \\
& management & $\begin{array}{l}\text { Request training for untrained } \\
\text { personnel }\end{array}$ \\
& & \\
& &
\end{tabular}




\begin{tabular}{|llll|}
\hline \multicolumn{1}{|c}{ ACTIVITY } & \multicolumn{1}{c}{ TIME FRAME } & \multicolumn{1}{c|}{ IN-CHARGE } & RESOURCES \\
$\begin{array}{l}\text { RTI training for } \\
\text { personnel }\end{array}$ & April 1997 & PopCouncil & PopCouncil \\
$\begin{array}{l}\text { Community awareness } \\
\text { and information } \\
\text { dissemination } \\
\text { - IEC materials }\end{array}$ & April 1997 & PopCouncil & \\
$\begin{array}{l}\text { - community } \\
\text { assembly, pre- } \\
\text { marriage } \\
\text { counseling, etc. }\end{array}$ & April-Dec 1997 & RHU staff & LGU funds for posters, \\
$\begin{array}{l}\text { Identification of RTI } \\
\text { cases; provision of } \\
\text { drugs }\end{array}$ & April- December 1997 & MO/RHM & \\
$\begin{array}{l}\text { Upgrading of lab } \\
\text { facilities }\end{array}$ & April 1997 & & Drugs from PopCouncil \\
$\begin{array}{l}\text { Preparation and } \\
\text { submission of reports }\end{array}$ & April-December 1997 & Trained RHU personnel & PopCouncil Forms \\
\hline
\end{tabular}

\section{Toro Hills Health Center, Quezon City}

\begin{tabular}{|lll|}
\hline \multicolumn{1}{|c}{ STRENGTHS } & LIMITATIONS & $\underline{\text { RECOMMENDATIONS }}$ \\
Presence of trained personnel & Sterilizer is broken & Immediate repair of sterilizer \\
Active CHVs & Lack of supply of drugs & Ask PopCouncil for drugs \\
Supportive LGU & Lack of IEC materials & $\begin{array}{l}\text { Ask support from IEC-oriented } \\
\text { agencies }\end{array}$ \\
Presence of health sub-station & Midwives have no RTI training & Train PHM \\
Good location & No med tech & Request for permanent med tech \\
& No reagents & Re-stock on reagents \\
\hline
\end{tabular}




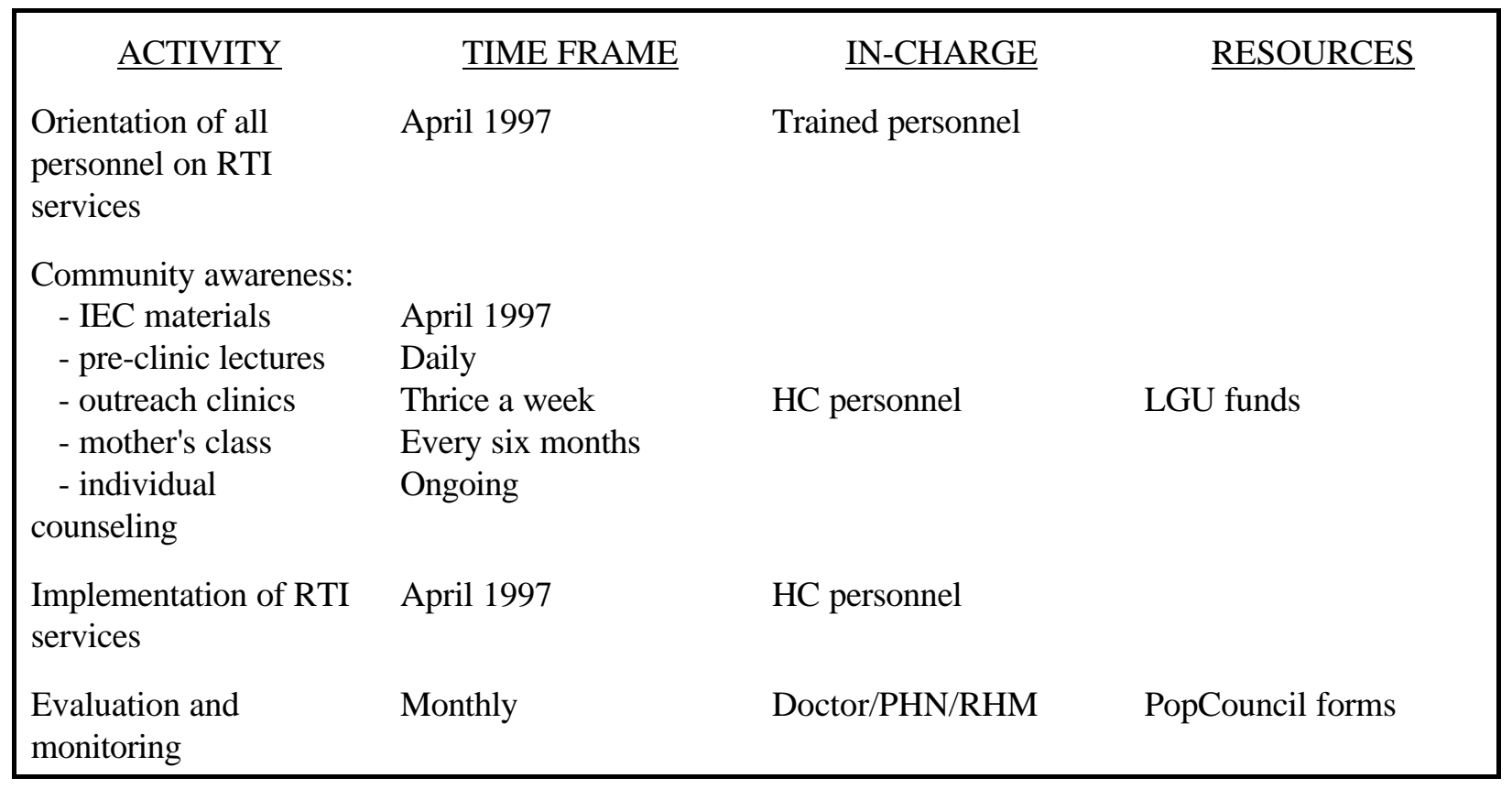




\section{Bernardo Health Center}

ACTIVITY

Feedback/Echo/Orientation for $\mathrm{CHO}, \mathrm{ACHO}$,

DHOs and other

Division heads

Health Center

Orientation

Awareness campaign

(pre-clinic lectures,

mothers' classes, $\mathrm{H}$ \&

W sessions, community assemblies

Implementation of the project

Evaluation/Monitoring - analysis of report -submission of reports
TIME FRAME

March 31, 1997

April 2-5, 1997

April 7-18, 1997

April-December 1997 on-going

Monthly

H.C. Management

Ms. Seares

Ms. Escorpiso

Dr. Abarquez

Ms. Escorpiso

Staff

Trained personnel

\section{RESOURCES}

Summary report

Flow Chart

Trained Personnel/HC

CHW Bgy. Officials

Supplies/Equipment Medicines

PopCouncil Forms
IEC materials 


\title{
CLOSING REMARKS
}

\author{
Dr. Nemesio Gako \\ Assistant Secretary \\ Department of Health, Manila
}

Thank you very much for giving me such a warm welcome. The presentations were all very good. It seems that you are all enthusiastic about this study. I am glad that this is so because it is certainly an important project.

One commitment that I would like to make today is that the DOH will supply RTI drugs for the Urban Health and Nutrition Project areas of this study. We would like to make a supplemental budget for this.

This concern about reproductive tract infections is timely because it is women's month this month. It is good, therefore, that we are focusing on some of the concerns of women, such as maternal and child health, domestic violence, and, in this case, RTIs. This project being supported by Population Council is one of the programs endorsed by the DOH. We are supporting this project because of the concern about the changing epidemiological patterns of disease brought about by rapid urbanization and industrialization. Today, there are many drugs used in treating STDs because of the existence of many resistant strains. Even the symptoms of STDs are changing. They used to be confined only to the genitals, but now we see them on the lips, on the skin, on the face, throat, and other parts of the body. In the past, condoms were enough to ensure one's health and safety, but this is not the case anymore. Now it is impossible to be totally safe. This has implications, especially for women. In fact, we can see this in cases of infertility and social stigma being placed upon women. I understand that you have been talking about these issues during the four days that you have been here. I am really glad that Population Council was able to give a venue for these issues to be brought up. I am sure that many of you had valuable learnings from this workshop. I can only hope that you will bring these back to your respective areas and that you will then share what you have learned. 
Thank you very much for attending this workshop. I know it was worth your while and would like to wish everyone a safe and pleasant trip home. 